\title{
Targeting interferon response genes sensitizes aromatase inhibitor resistant breast cancer cells to estrogen-induced cell death
}

Hye Joung Choi ${ }^{1 \dagger}$, Asona Lui ${ }^{1,2 \dagger}$, Joshua Ogony ${ }^{1}$, Rifat $\operatorname{Jan}^{3}$, Peter J Sims ${ }^{4}$ and Joan Lewis-Wambi ${ }^{1,2^{*}}$

\begin{abstract}
Introduction: Estrogen deprivation using aromatase inhibitors (Als) is currently the standard of care for postmenopausal women with hormone receptor-positive breast cancer. Unfortunately, the majority of patients treated with Als eventually develop resistance, inevitably resulting in patient relapse and, ultimately, death. The mechanism by which resistance occurs is still not completely known, however, recent studies suggest that impaired/defective interferon signaling might play a role. In the present study, we assessed the functional role of IFITM1 and PLSCR1; two well-known interferon response genes in Al resistance.

Methods: Real-time PCR and Western blot analyses were used to assess mRNA and protein levels of IFITM1, PLSCR1, STAT1, STAT2, and IRF-7 in Al-resistant MCF-7:5C breast cancer cells and Al-sensitive MCF-7 and T47D cells. Immunohistochemistry $(\mathrm{IHC})$ staining was performed on tissue microarrays consisting of normal breast tissues, primary breast tumors, and Al-resistant recurrence tumors. Enzyme-linked immunosorbent assay was used to quantitate intracellular IFNa level. Neutralizing antibody was used to block type 1 interferon receptor IFNAR1 signaling. Small interference RNA (siRNA) was used to knockdown IFITM1, PLSCR1, STAT1, STAT2, IRF-7, and IFNa expression.

Results: We found that IFITM1 and PLSCR1 were constitutively overexpressed in Al-resistant MCF-7:5C breast cancer cells and Al-resistant tumors and that siRNA knockdown of IFITM1 significantly inhibited the ability of the resistant cells to proliferate, migrate, and invade. Interestingly, suppression of IFITM1 significantly enhanced estradiol-induced cell death in Al-resistant MCF-7:5C cells and markedly increased expression of p21, Bax, and Noxa in these cells. Significantly elevated level of IFNa was detected in Al-resistant MCF-7:5C cells compared to parental MCF-7 cells and suppression of IFNa dramatically reduced IFITM1, PLSCR1, p-STAT1, and p-STAT2 expression in the resistant cells. Lastly, neutralizing antibody against IFNAR1/2 and knockdown of STAT1/STAT2 completely suppressed IFITM1, PLSCR1, p-STAT1, and p-STAT2 expression in the resistant cells, thus confirming the involvement of the canonical IFNa signaling pathway in driving the overexpression of IFITM1 and other interferon-stimulated genes (ISGs) in the resistant cells.
\end{abstract}

Conclusion: Overall, these results demonstrate that constitutive overexpression of ISGs enhances the progression of Al-resistant breast cancer and that suppression of IFITM1 and other ISGs sensitizes Al-resistant cells to estrogen-induced cell death.

\footnotetext{
* Correspondence: jlewis-wambi@kumc.edu

${ }^{\dagger}$ Equal contributors

${ }^{1}$ Department of Cancer Biology, University of Kansas Medical Center, Kansas

City 66160, KS, USA

${ }^{2}$ Department of Physiology, University of Kansas Medical Center, Kansas City

66160, KS, USA

Full list of author information is available at the end of the article
}

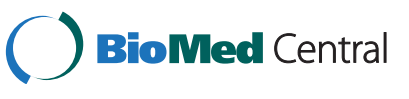

(c) 2015 Choi et al.; licensee BioMed Central. This is an Open Access article distributed under the terms of the Creative Commons Attribution License (http://creativecommons.org/licenses/by/4.0), which permits unrestricted use, distribution, and reproduction in any medium, provided the original work is properly credited. The Creative Commons Public Domain Dedication waiver (http://creativecommons.org/publicdomain/zero/1.0/) applies to the data made available in this article, unless otherwise stated. 


\section{Introduction}

Aromatase inhibitors (AIs) are more effective than the antiestrogen tamoxifen at inhibiting the growth and proliferation of estrogen receptor (ER)-positive breast cancer [1] and these agents are now front-line treatments for postmenopausal women with hormone receptorpositive breast cancer in both the adjuvant and metastatic setting [2,3]. AIs suppress estrogen synthesis in postmenopausal women by inhibiting the aromatase enzyme, which catalyzes the conversion of androgens to estrogens $[1,2,4,5]$. Unfortunately, the majority of patients treated with AIs eventually develop resistance to these drugs [6] and when resistance occurs it is unclear which endocrine therapy is the most appropriate. Recently, there has been increasing clinical evidence to suggest that $17 \beta$-estradiol $\left(\mathrm{E}_{2}\right)$ would be an appropriate and effective treatment option for postmenopausal patients with AI-resistant breast cancer [7,8]. Indeed, preclinical studies from our laboratory [9-12] and other investigators $[13,14]$ ) have previously shown that long term estrogen deprivation of ER-positive MCF-7 breast cancer cells causes them to lose their dependency on estradiol for proliferation, which recapitulates acquired resistance to aromatase inhibitors in postmenopausal women, and that these AI-resistant breast cancer cells paradoxically undergo apoptosis in the presence of estradiol $[10-12,15,16]$. The ability of estradiol to induce apoptosis in AI-resistant breast cancer cells was previously shown to be mediated, in part, by the mitochondria death pathway [11]; however, more recent findings suggest that dysregulation of the interferon signaling pathway might also play a role in estradiol-induced cell death [17].

Interferons (IFNs) are a class of glycoproteins known as cytokines that are produced by immune cells of most vertebrates and are secreted in response to viral infections, tumors, and other pathogenic microbial agents [18]. IFNs diffuse to the surrounding cells and bind to high affinity cell surface type I (IFN $\alpha / \beta)$ and type II (IFN $\gamma$ ) receptors (IFNAR1/2), leading to phosphorylation and activation of JAK1, JAK2 and Tyk2. Activated JAKs phosphorylate and activate STAT1 and STAT2, resulting in the formation of STAT1-STAT1 homodimers and STAT1-STAT2 heterodimers. The dimers are transported to the nucleus by importins and bind to IFN-stimulated response elements (ISREs) to activate the transcription of interferon-stimulated genes (ISGs), such as IFITM1, PLSCR1, STAT1, IFI27 and IFIT1 [18-20]. The interferon signaling pathway plays an important role in the proper functioning of the immune system [21] and there is strong evidence that its dysregulation, resulting in constitutive overexpression of ISGs contributes to tumorigenesis [22] and possibly drug resistance [23]. Indeed, our laboratory has previously shown through microarray analysis that immune response and interferon signaling pathways are significantly altered in AI-resistant breast cancer cells and that several interferon response genes including IFITM1, PLSCR1 and STAT1 are constitutively overexpressed in AI-resistant breast cancer cells [17,24]. At present, however, the functional significance of the interferon signaling pathway in AI-resistance or its potential involvement in estradiol-induced cell death is not known.

Interferon-inducible transmembrane protein 1 (IFITM1) is a cell surface $17 \mathrm{kDa}$ membrane protein that is a member of the IFN-inducible transmembrane protein family that includes IFITM2, IFITM3 and IFITM5 [25,26]. The IFITM1 gene is located on the short arm of chromosome 11 (11p15.5) and is 3,956 bases in length. IFITM1 expression is highly induced by IFN $\alpha$ and IFN $\beta$ to a lesser extent, IFNY [27]. IFITM1 was initially identified as Leu13, a leukocyte antigen that is part of a membrane complex involved in the transduction of antiproliferative and homotypic adhesion signals in lymphocytes [28,29]. IFITM1 is also known to play a critical role in blocking early stages of viral replication and it potently restricts entry and infections by a number of highly pathogenic viruses, including HIV-1, filovirus, and SARS coronavirus [30]. More recently, there has been increasing evidence to suggest that high expression of IFITM1 plays a role in the progression of several cancers including head and neck cancer, serous ovarian cancer, gastric cancer and colorectal cancer [29,31-33]. However, its role in breast cancer or endocrine resistance is not known.

Phospholipid scramblase 1 (PLSCR1) is a $35 \mathrm{kDa}$ multiply palmitoylated protein that is localized in the cell membrane and is responsible for mediating the translocation of negatively-charged phospholipids from the inner-leaflet of the plasma membrane to the outerleaflet during cellular injury and apoptosis [34,35]. PLSCR1 is highly induced by type 1 IFNs and it plays an antagonistic role in leukemia [36] and ovarian cancer [37]; however, its role in breast cancer is unknown.

In the present study, we investigated the functional role of IFITM1 and PLSCR1 in AI-resistant breast cancer. We found that IFITM1 and PLSCR1 were constitutively overexpressed in AI-resistant MCF-7:5C breast cancer cells and AI-resistant tumors and that knockdown of IFITM1 significantly reduced their ability to proliferate, invade, and migrate. Most interestingly, we found that suppression of IFITM1 sensitized AI-resistant MCF-7:5C cells to estradiol-induced cell death. Suppression of IFN $\alpha$ level via siRNA knockdown of IRF-7 confirmed that the constitutive overexpression of IFITM1 and PLSCR1 in the resistant cells was driven by increased intracellular levels of IFN $\alpha$. Further analysis using neutralizing antibody against IFNAR and siRNA knockdown of STAT1 and STAT2 revealed complete suppression of IFITM1, PLSCR1, p-STAT1 and p-STAT2 
in the resistant cells, thus confirming a critical role for canonical IFN $\alpha$ signaling in the regulation of IFITM1 and other ISGs in the resistant cells.

\section{Methods \\ Reagents}

RPMI 1640 and fetal bovine serum (FBS) were obtained from Invitrogen Inc. (Grand Island, NY, USA). The antibiotic/antimycotic solution (containing 10,000 U/mL penicillin and $10 \mathrm{mg} / \mathrm{mL}$ streptomycin, $25 \mu \mathrm{g} / \mathrm{mL}$ of Fungizone $^{\circ}$ ), NEAA (MEM Non-Essential Amino Acids), L-glutamine, and TrypLE (containing trypsin and ethylenediaminetetraacetic acid (EDTA)) were obtained from Invitrogen. Insulin (bovine pancrease), human recombinant interferon-alpha (IFN $)$ and $17 \beta$-estradiol $\left(\mathrm{E}_{2}\right)$ were obtained from Sigma-Aldrich Co. (St. Louis, MO, USA). $E_{2}$ was dissolved in ethanol at a stock concentration of $1 \mu \mathrm{M}$ $\left(10^{-6} \mathrm{M}\right)$ and stored at $-20^{\circ} \mathrm{C}$. Anti-PLSCR1, anti-IFITM1, anti-IRF-7, anti-STAT1, anti-Bax, anti-Noxa, anti-PUMA, anti-p53, anti-p21, anti-Lamin B, anti-IFNAR ( $\alpha$ - IFNAR), anti-p-STAT2 (Tyr690) and anti-ER $\alpha$ antibodies were purchased from Santa Cruz Technology Inc. (Santa Cruz, CA, USA); anti- poly ADP ribose polymerase (PARP) and antip-STAT1 (Y701) were purchased from Cell Signaling Technology (Beverly, MA, USA), and anti- $\beta$-actin was purchased from Sigma-Aldrich. PLSCR1 monoclonal antibody 4D2 was a kind gift from Dr. Peter Sims (University of Rochester, NY, USA).

\section{Cell lines and culture conditions}

The ER-positive hormone-dependent human breast cancer cell lines, MCF-7 and T47D, were originally obtained from the American Type Culture Collection (Manassas, VA, USA) and were maintained in full serum medium composed of RPMI-1640 medium, 10\% FBS, $2 \mathrm{mM}$ glutamine, penicillin at $100 \mathrm{U} / \mathrm{mL}$, streptomycin at $100 \mu \mathrm{g} / \mathrm{mL}, 1 \times$ NEAA (Invitrogen) and bovine insulin at $6 \mathrm{ng} / \mathrm{mL}$ (Sigma-Aldrich). The long term estrogen deprived human breast cancer cell line MCF-7:5C [9,12] was cloned from parental MCF-7 cells following long term ( $>12$ months) culture in estrogen-free medium composed of phenol red-free RPMI-1640, 10\% FBS treated three times with dextran-coated charcoal (SFS), $2 \mathrm{mM}$ glutamine, bovine insulin at $6 \mathrm{ng} / \mathrm{mL}$, penicillin at $100 \mathrm{U} / \mathrm{mL}$, streptomycin at $100 \mu \mathrm{g} / \mathrm{mL}$, and $1 \times$ NEAA. The MCF7:5C cell line was used as a model of AI resistance because it proliferates despite being deprived of estrogen $[9,12]$. Cells were cultured at $37^{\circ} \mathrm{C}$ under $5 \% \mathrm{CO}_{2}$ and were subcultured every three to four days.

\section{MTT assay}

For determining cell viability, the 3-(4,5-dimethylthiazol2-Yl)-2,5-diphenyltetrazolium bromide (MTT) assay was used. MCF-7 and MCF-7:5C cells were seeded onto 24-well plates at a density of $5 \times 10^{4}$ cells per well in culture media and incubated until about $60 \%$ to $70 \%$ confluency, before the start of experimental treatments. The stock solution of $E_{2}$ was diluted in the culture medium before addition to each well at desired final concentrations, and the treatments usually lasted 24 hours. Following the treatments as indicated, $50 \mu \mathrm{l}$ of MTT solution (at $5 \mathrm{mg} / \mathrm{mL}$ ) was added to each well at a final concentration of $500 \mu \mathrm{g} / \mathrm{mL}$, and the mixture was further incubated for four hours at $37^{\circ} \mathrm{C}$. An aliquot $(500 \mu \mathrm{l})$ of the solubilizing solution (dimethyl sulfoxide (DMSO):ethanol, $1: 1, \mathrm{v}: \mathrm{v})$ was then added to each well, and the absorbance was read with a UV max microplate reader (Molecular Device, Palo Alto, CA, USA) at $560 \mathrm{~nm}$. The relative cell density was expressed as a percentage of the control that was not treated with $\mathrm{E}_{2}$.

\section{Western blotting}

For Western blotting, cells were washed first and then suspended in $100 \mu \mathrm{L}$ lysis buffer (RIPA buffer, $150 \mathrm{mM}$ $\mathrm{NaCl}, 1.0 \%$ IGEPAL $^{\circ}$ CA-630, $0.5 \%$ sodium deoxycholate, $0.1 \%$ SDS, $50 \mathrm{mM}$ Tris, $\mathrm{pH}$ 8.0, protease inhibitor cocktail, and phosphatase inhibitor). The amount of proteins was determined using the Bio-Rad protein assay (Bio-Rad, Hercules, CA, USA). An equal amount of proteins was loaded in each lane. The proteins were separated by $4 \%$ to $12 \%$ SDS-polyacrylamide gel electrophoresis (SDS-PAGE) and electrically transferred to a polyvinylidene difluoride membrane (Bio-Rad). After blocking the membrane using $5 \%$ non-fat milk, target proteins were detected using specific antibodies. Thereafter, horseradish peroxidase (HRP)-conjugated anti-rabbit (or anti-mouse) immunoglobulin G (IgG) was applied as the secondary antibody and the positive bands were detected using Amersham ECL Plus Western blotting detection reagents (GE Health Care, Piscataway, NJ, USA).

\section{Nuclear and cytoplasmic fractionation}

For protein localization, the nuclear and cytosolic fractions were prepared using the cytosolic/nuclear fractionation kit obtained from Biovision Inc. (Mountain View, CA, USA), by following the instructions of the manufacturer. Briefly, cells were suspended in hypotonic buffer and lysed with the proprietary detergent from the kit. Samples were spun at $800 \times g$ for 10 minutes at $4^{\circ} \mathrm{C}$. The supernatant was collected, spun five minutes at $16,000 \times g$ to remove any remaining nuclei, and then transferred to a new microtube (cytosolic protein fraction). The original pellet was resuspended in the nuclear extraction buffer and then incubated on ice for 40 minutes with occasional vortexing. After salt extraction, the nuclear pellet was centrifuged at $16,000 \times g$ for 10 minutes, and the supernatant was saved as the nuclear extract. Extracts were stored in aliquots in $-80^{\circ} \mathrm{C}$ until use. 


\section{Annexin $\mathrm{V}$ staining for apoptosis}

An annexin V-fluorescein isothiocyanate (FITC)-labeled Apoptosis Detection Kit I (Pharmingen, San Diego, CA, USA) was used to detect and quantify apoptosis by flow cytometry according to the manufacturer's instructions. In brief, MCF-7:5C cells $\left(1 \times 10^{6}\right.$ cells $\left./ \mathrm{mL}\right)$ were seeded in $100-\mathrm{mm}$ dishes and cultured overnight in estrogenfree RPMI 1640 medium containing 10\% SFS. The next day, cells were treated with $<0.1 \%$ ethanol vehicle (control) and $E_{2}(1 \mathrm{nM})$ for 96 hours and then harvested in cold PBS (Invitrogen) and collected by centrifugation for $10 \mathrm{mi}$ nutes at $500 \times g$. Cells were then resuspended at a density of $1 \times 10^{6}$ cells $/ \mathrm{mL}$ in $1 \times$ binding buffer (HEPES buffer, $10 \mathrm{mM}, \mathrm{pH} 7.4,150 \mathrm{mM} \mathrm{NaCl}, 5 \mathrm{mM} \mathrm{KCl}, 1 \mathrm{mM} \mathrm{MgCl} 2$ and $1.8 \mathrm{mM} \mathrm{CaCl} 2$ ) and stained simultaneously with FITC-labeled annexin V (25 ng/mL; green fluorescence) and propidium iodide (PI) $(50 \mathrm{ng} / \mathrm{mL})$. PI was provided as a $50 \mu \mathrm{g} / \mathrm{mL}$ stock (Pharmingen) and was used as a cell viability marker. Cells were analyzed using the BD LSR II flow cytometer (BD Bioscience, San Jose, CA, USA), and the data were analyzed with CellQuest software.

\section{Immunofluorescence microscopy}

Cells grown on glass coverslips were washed in PBS and fixed with $4 \%$ formaldehyde in PBS for 30 minutes. After permeabilization by $0.2 \%$ Triton X-100 in PBS for $5 \mathrm{mi}-$ nutes, cells were incubated with $0.1 \mathrm{mg} / \mathrm{mL}$ RNAse in $2 \%$ whole goat serum/PBS for 30 minutes at $37^{\circ} \mathrm{C}$, followed by incubation with PLSCR1 (4D2) or IFITM1 antibody, $5 \mu \mathrm{g} / \mathrm{mL}$ in $2 \%$ goat serum/PBS (Jackson Immuno Research Labs Inc., West Grove, PA, USA) for one hour. Cells were stained with FITC-conjugated labeled goat anti-mouse IgG, $4 \mu \mathrm{g} / \mathrm{mL}$ in PBS for one hour, followed by nuclear counterstain with 4',6-diamidino-2-phenylindole (DAPI) $0.1 \mu \mathrm{g} / \mathrm{mL}$ in PBS for $10 \mathrm{mi}$ nutes. Coverslips were mounted on glass slides with Vectashield Mounting medium (Vector Laboratories, Burlingame, CA, USA), and samples were analyzed on a Bio-Rad MRC-1024 laser scanning confocal microscope equipped with a Zeiss X60 objective. Images were collected using Bio-Rad's Laser Sharp software. Specificity of staining observed for PLSCR1 mab 4D2 was evaluated by cell staining with the identical concentration of an isotype-matched antibody.

\section{Cell cycle analysis}

MCF-7:5C cells were transfected with siCon, siPLSCR1 or siIFITM1 for 72 hours and then harvested by trypsinization and washed once with phosphate-buffered saline (PBS, $\mathrm{pH}$ 7.4). After centrifugation, cells were resuspended in $1 \mathrm{~mL}$ of $0.9 \% \mathrm{NaCl}$, followed by addition of $2.5 \mathrm{~mL}$ of ice-cold $90 \%$ ethanol. After incubation at room temperature for 30 minutes, cells were centrifuged and the supernatant was removed. Cells were resuspended in $1 \mathrm{~mL}$ PBS containing $50 \mu \mathrm{g} / \mathrm{mL}$ PI and $100 \mu \mathrm{g} / \mathrm{mL}$ ribonuclease $\mathrm{A}$ and incubated at $37^{\circ} \mathrm{C}$ for 30 minutes. Flow cytometric analyses were performed using the BD LSR II flow cytometer (BD Bioscience, San Jose, CA, USA).

\section{Enzyme-linked immunosorbent assay}

Measurement of human interferon- $\alpha$ (IFN $\alpha$ ) was conducted by enzyme-linked immunosorbent assay (ELISA) (PBL Interferon Source, Piscataway, NJ, USA). One million MCF-7 or MCF-7:5C cells were seeded in six-well plates and allowed to acclimatize overnight. They were then treated with $250 \mathrm{U} / \mathrm{mL}$ human recombinant IFNa for 24 hours. Cells and supernatants were harvested after 24 hours and kept at $-80^{\circ} \mathrm{C}$ until analysis. Protein was extracted by sonication in RIPA buffer supplemented with protease and phosphatase inhibitors. Supernatants and lysates were purified by centrifugation and analyzed for the presence of IFN $\alpha$ according to the manufacturer's instructions.

\section{IFNAR neutralization}

In order to achieve neutralization of type 1 interferon, IFNAR, MCF-7 and MCF-7:5C cells were pretreated with $5 \mu \mathrm{g} / \mathrm{mL}$ anti-IFNAR1/2/MMHAR2 from Millipore, Temecula, CA, USA (cat\# MAB1155) for four hours and then treated overnight with $20 \mathrm{U} / \mathrm{mL}$ human recombinant IFN $\alpha$ (Sigma) or $1 \mathrm{nM} \mathrm{E}_{2}$ (Sigma) where indicated. Cells were harvested by cell scraping for Western blot and by trypsinization for cell viability analysis with trypan blue count.

\section{Small interfering RNA transfections}

For small interfering RNA (siRNA) knockdown experiments, MCF-7:5C and MCF-7 cells were transiently transfected with PLSCR1-siRNA (h) (siPLSCR1), IFITM1siRNA (h) (siIFITM1), STAT1-siRNA (h) (siSTAT1),

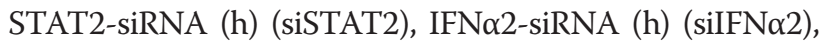
IRF-7 siRNA (h) (siIRF-7), Bax-siRNA (h) (siBax), NoxasiRNA (h) (siNoxa), or nontarget siRNA (siCon). The siPLSCR1 (cat\# sc-44028), siIFITM1 (cat\# sc-44549), siSTAT1 (cat\# sc-44123), siSTAT2 (cat\# sc-29492), siIFN $\alpha$ (cat\# sc-63324), siIRF-7 (cat\# 38011) and siRNA negative control (cat\# sc-37007) were purchased from Santa Cruz Biotechnology, and siBax and siNoxa were purchased from Thermo Fisher Scientific (Pittsburg, PA, USA). All of the siRNAs were pools of three targetspecific 20 to $25 \mathrm{nt}$ siRNAs. MCF-7:5C or MCF-7 cells were seeded the night before transfection at a density of $30 \%$ to $50 \%$ confluence by the time of transfection. Twenty nmol of siPLSCR1, siIFITM1, siSTAT1 and siRNA negative control were used for transfection using Lipofectamine 2000 (Invitrogen, San Diego, CA, USA) according to the manufacturer's instructions. Transfected cells were maintained in culture for two days before harvesting and 
further analyses. The efficiency of the siRNA knockdown was determined by Western blot analysis.

\section{Short hairpin RNA (shRNA) knockdown}

MCF-7:5C cells were transiently transfected with IFITM1shRNA plasmid (h) (shIFITM1, cat\# sc-44549-SH) or control-shRNA (shControl, cat\# sc-108060) plasmid which were purchased from Santa Cruz Biotechnology. IFITM1 shRNA plasmid is a pool of three different shRNA plasmids. sc-44549-SHA: Hairpin sequence: GATCCCA CACTTCTCAAACCTTCATTCAAG AGATGAAGGT TTGAGAAGTGTGTTTTT. Corresponding siRNA sequences (sc-44549A): Sense: CACACUUCUCAAACC UUCAtt; Antisense: UGAAGGUUUGAGAAGUGUGtt. sc-44549-SHB: Hairpin sequence: GATCCCTGTGACA GTCTACCATATTTCAAGAGAATA TGGTAGACTGT CACAGTTTTT. Corresponding siRNA sequences (sc44549B): Sense: CUGUGACAGUCUACCAUAUtt; Antisense: AUAUGGUAGACUGUCACAGtt. sc-44549-SHC: Hairpin sequence: GATCCCTGTCTACAGTGTCATTC ATTCAAGAGATGAATGACA CTGTAGACAGTTTTT. Corresponding siRNA sequences (sc-44549C): Sense: CUGUCUACAGUGUCAUUCAtt; Antisense: UGAAUG ACACUGUAGACAGtt. MCF-7:5C cells were seeded in six-well plates and at $50 \%$ to $70 \%$ confluency were transfected with $3 \mu \mathrm{g}$ of shIFITM1 or shControl plasmid using Lipofectamine 2000 (Invitrogen, San Diego, CA, USA) according to the manufacturer's instructions. The transfected cells were incubated for 24 or 48 hours and the efficiency of the shRNA knockdown was determined by Western blot analysis and real-time PCR. The knockdown cells were then used for additional experiments.

\section{Cell migration and invasion assay}

Cell migration was measured in a Boyden chamber using Transwell filters obtained from Corning (Cambridge, MA, USA). MCF-7:5C cells $\left(1 \times 10^{5}\right)$ in $0.5 \mathrm{~mL}$ serumfree medium were placed in the upper chamber, and the lower chamber was loaded with $0.8 \mathrm{~mL}$ medium containing $10 \%$ charcoal-stripped FBS. Cells that migrated to the lower surface of the filters were stained with Wright Giemsa solution, and five fields of each well were counted after 24 hours of incubation at $37^{\circ} \mathrm{C}$ with $5 \%$ $\mathrm{CO}_{2}$. Three wells were examined for each condition and cell type, and the experiments were repeated in triplicate. Cell invasion assay was performed using a Chemicon Cell Invasion kit (Chemicon International, Temecula, CA, USA) in accordance with the manufacturer's protocol. Cells $\left(1 \times 10^{5} / \mathrm{mL}\right)$ were seeded onto 12 -well cell culture chambers using inserts with $8 \mu \mathrm{M}$ pore size polycarbonate membrane over a thin layer of extracellular matrix (ECM). Following incubation of the plates for 24 hours at $37^{\circ} \mathrm{C}$, cells that had invaded through the ECM layer and migrated to the lower surface of the membrane were stained and counted under the microscope in at least ten different fields and photographed.

\section{RNA isolation and RT-PCR analysis}

Total RNA was isolated from cultured cells using the RNeasy ${ }^{\circ}$ Mini Kit (Qiagen, Venlo, Netherlands) according to the manufacturer's procedure. First strand cDNA synthesis was performed from $2.5 \mu \mathrm{g}$ total RNA using Super- Script Reverse Transcriptase (Invitrogen). cDNA was amplified in a $15-\mu$ l PCR mixture containing $1 \mathrm{mM}$ dNTPs, $1 \times$ PCR buffer, $2.5 \mathrm{mM} \mathrm{MgCl} 2$ and $1 \mathrm{U}$ DNA Taq polymerase (Promega, Madison, WI, USA) with 25 pmol of primers specific for human PLSCR1 (sense: $5^{\prime}$ CATTCACCGGGCTCTCTAC-3'; antisense: 5'-GGCA GCTGGGCA ATCTTGCA-3'), IFITM1 (sense: 5' -GGA TTTCGGCTTGTCCCGAG-3'; antisense: 5' - CCATG TGGAAGGGAGGGCTC-3'), IRF-9 (sense: 5' -TTCTG TCCCTGGTGTAGAGCCT-3', antisense: 5' - TTTCAG GACACGATTATCACGG-3'), IRF-7 sense: 5'-GAGC CCTTACCTCCC CTGTTAT-3', antisense: 5"'-CCAC TGCAGCCCCTCATAG-3', IFI27 (sense: 5'- GCCT CTGG CTCTGCCGTAGTT-3', antisense: 5'-ATGGA GGACGAGGCGATTCC-3'), IFIT1 (sense 5'-TCTCA GAGGAGCCTGGCTAA-3', antisense 5' -CCAGACTA TCCTTGACCTGATGA-3'), MX1 (sense: $5^{\prime}$-CTTTCC AGTCCAGCTCGGCA-3', antisense: 5' -AGCTGCTGG CCGTACGT CTG-3'), OAS1 sense: 5'-TGAGGTCC AGGCTCCACGCT-3', antisense: 5'-GCAGGTC GGT GCACTCCTCG-3'), STAT1 (sense: 5'-GGCACCAGA ACGAATGAGGG-3', antisense: 5' -CCATCGTGCACA TGGTGGAG-3', STAT2 (sense: 5'-GCAGCACAATTT GCGGAA-3', antisense: 5' -ACAGGTGTTTCGAGAAC TGGC-3'). The condition in the logarithmic phase of PCR amplification was as follows: five minutes initial denaturation at $94^{\circ} \mathrm{C}$, one minute denaturation at $94^{\circ} \mathrm{C}$, 35 seconds annealing at $67^{\circ} \mathrm{C}$ and $1.5 \mathrm{~min}$ extension at $72^{\circ} \mathrm{C}$ for 30 cycles. The number of amplification cycles during which PCR product formation was limited by template concentration was determined in pilot experiments. PUM1 was used as the internal control (sense: 5'-TCACCGAGGCCCCTCTGAACCCTA-3'; antisense: 5'-GGCAGTAATCTCCTTCTGCATCC T-3'). The reproducibility of the quantitative measurements was evaluated by three independent CDNA syntheses and PCR amplification from each preparation of RNA. Densitometric analysis was performed using Scion Image software (Scion Corp, Frederick, MD, USA), and the relative mRNA expression level was determined as the ratio of the signal intensity of the target to that of PUM1.

\section{Tissue microarray construction and immunohistochemistry}

Paraffin-embedded de-identified human breast cancer tissue samples were collected from the Tumor Bank facility at The Research Institute of Fox Chase Cancer 
Center (Philadelphia, PA, USA) and the University of Kansas Medical Center (KUMC) and the protocols were reviewed and approved by the Institutional Review Board at Fox Chase Cancer Center and KUMC. The archived tumor samples were collected from patients $(\mathrm{N}=40)$ who were initially treated with Arimidex and either responded or responded but then developed recurrence disease with an average time to disease progression (TTP) of 93 months. Patients provided written informed consent for the use of their tumor samples. Tissue microarray (TMA) slides were constructed from 40 matching primary and AI-resistant tumors using duplicate cores of $0.6 \mathrm{~mm}$ per tumor sample. Normal mammary tissue samples $(\mathrm{N}=10)$ were also included on the TMA. For immunohistochemistry assays, tissue microarray slides were incubated at room temperature for 20 minutes with antibodies against IFITM1 (Santa Cruz Biotechnology) and PLSCR1 (Chemicon Inc.) applied at 1:100 dilution in antibody diluent (Dako, Carpenteria, CA, USA). A secondary anti-mouse antibody polymer conjugated with HRP (Dako) was applied for 30 minutes and 3,3'-diaminobenzidine $(\mathrm{DAB})$ was used to produce visible, localized staining viewable with light microscopy. Sections without primary antibody served as negative controls. A semiautomated quantitative image analysis system, ACIS II (ChromaVision Medical Systems, Inc., San Juan Capistrano, CA, USA), was used to quantitate the staining of the TMA slides. For immunohistochemical analysis, the scores were determined by combining the proportion of positively stained tumor cells and the intensity of staining, giving rise to a Staining Index (SI) value for each sample. The proportion of positively stained tumor cells was graded as follows: $0(<5 \%$ positively stained tumor cells), 1 ( $5 \%$ to $25 \%$ positive tumor cells), 2 ( $25 \%$ to $50 \%$ positive tumor cells), 3 ( $50 \%$ to $75 \%$ positive tumor cells) and 4 ( $>75 \%$ positive tumor cells). The intensity of staining was recorded on a scale of 0 (no staining), 1 (weak staining, light brown), 2 (moderate staining, yellowish brown) and 3 (strong staining, brown). The SI value was calculated as follows: $\mathrm{SI}=$ staining intensity $\times$ proportion of positively stained tumor cells. Scores were evaluated comparatively for the expression of IFITM1 and PLSCR1 in breast tumors by SIs (scored as $0,1,2,3,4,6$ or 9). An optimal cutoff value was identified, and the SI score of $\geq 6$ was used to define tumors with high expression and SI $\leq 3$ as tumors with low expression of IFITM1 and PLSCR1. Immunohistochemistry (IHC) analysis was also performed on MCF-7, T47D and MCF-7:5C breast cancer cells to detect IFITM1 and PLSCR1 protein expression. Cells were cultured in their appropriate medium, harvested by cell scraper before reaching confluence, washed twice with PBS and fixed in 10\% formalin for 16 hours. Each cell line was pelleted and made into a cell block. One $\mathrm{H}$ \& E stain and two IHC stains for PLSCR1 and IFITM1 were subsequently performed for each cell line. Pretreatments consisted of enzyme digestion or other heat mediated retrieval methods. Sections were stained on a Dako Autostainer using either an Envision PlusHRP polymer (Dako) or horse anti-mouse IgG-biotin (Vector Laboratories, Inc. Burlingame, CA, USA), streptavidinHRP (Jackson Labs) and AEC (Dako), and counterstained in hematoxylin.

\section{Statistical analysis}

At least three separate experiments were performed for each measurement. All quantitative data were expressed as mean S.D. Comparisons between two groups were analyzed using two-way analysis of variance (ANOVA), with $P$ value of $<0.05$ considered to be statistically significant.

\section{Results}

IFITM1 and PLSCR1 are constitutively overexpressed in Al-resistant human breast cancer cells and Al-resistant tumors

Microarray studies previously revealed that the interferon signaling pathway was altered in AI-resistant breast cancer cells compared with AI-sensitive cells [17]. To understand better the role of the interferon signaling pathway in AI-resistant breast cancer we measured the basal expression of two well-known interferon stimulated proteins, IFITM1 and PLSCR1, in AI-resistant MCF-7:5C breast cancer cells and AI-sensitive MCF-7 and T47D cells. Our data showed that IFITM1 and PLSCR1 were constitutively overexpressed at the protein (Figure 1A) and mRNA level (Figure 1B) in AI-resistant MCF-7:5C cells but were almost undetectable at the protein and mRNA level in AI-sensitive MCF-7 and T47D cells. Notably, we also found that several other ISGs including IFI27, IFIT1, OAS1, MX1, IRF-7, IRF-9, STAT1 and STAT2 were constitutively overexpressed in AIresistant MCF-7:5C cells compared with MCF-7 cells (Additional file 1: Figure S1). Immunocytochemistry (ICC) staining of MCF-7, T47D and MCF-7:5C cells also showed that IFITM1 and PLSCR1 were overexpressed in MCF-7:5C cells compared to MCF-7 and T47D cells (Figure 1C). Next, we investigated the clinical significance of IFITM1 and PLSCR1 expression in AI-resistant (recurrence) breast cancer by performing IHC staining on normal breast tissue, primary breast tumors $(\mathrm{N}=40)$ and AI-resistant recurrence breast tumors $(\mathrm{N}=40)$. We found that IFITM1 and PLSCR1 proteins were overexpressed in $90 \%$ of the AI-resistant (recurrence) tumors (36 of 40 samples) compared with only $20 \%$ of the primary tumors (8 out of 40 samples); however, in normal breast tissue PLSCR1 and IFITM1 proteins were undetectable (Figure 1D). As shown in Table 1, stained slides were scored in terms of intensity and distribution. 


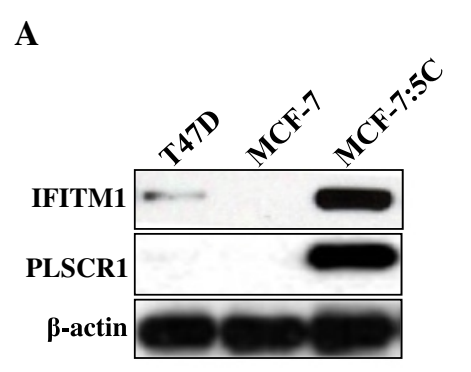

C

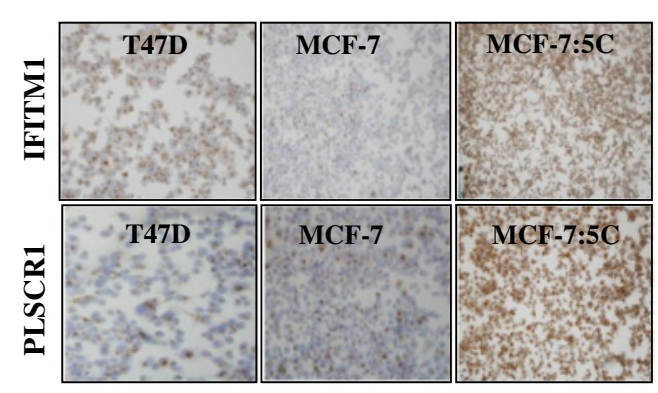

B

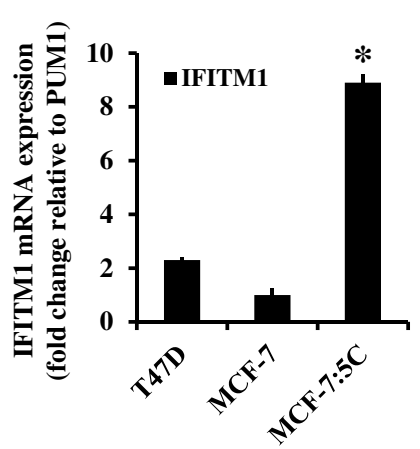

D

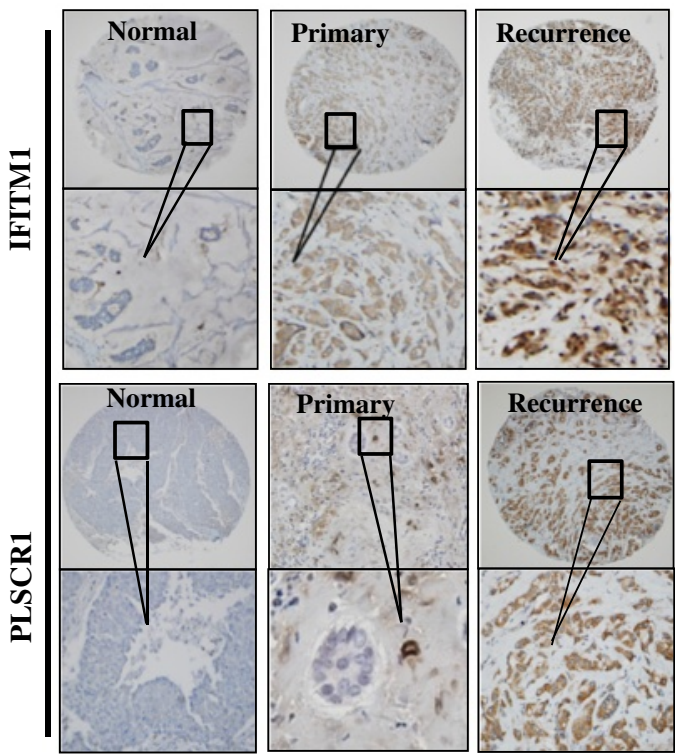

Figure 1 IFITM1 and PLSCR1 expression in endocrine-sensitive and Al-resistant breast cancer cells. (A) The cell extracts isolated from the indicated cell lines (endocrine sensitive-T47D/MCF-7, Al-resistant MCF-7:5C) were detected by Western blot analysis for PLSCR1 and IFITM1 protein and $\beta$-actin as a loading control. (B) Total RNA was extracted from each cell line and IFITM1 (upper panel) and PLSCR1 (lower panel) mRNA was determined by real-time PCR. Fold change was determined for each cell line relative to the internal control gene PUM1. Each value is a mean \pm SD from three experiments. ${ }^{*} P<0.05$ (C) Relative intensity of the IFITM1 or PLSCR1 in T47D, MCF-7 and MCF-7:5C cells were determined by immunocytochemistry (ICC) staining. (D) Immunohistochemistry (IHC) staining for IFITM1 or PLSCR1 was performed on tissue microarrays generated from normal breast tissue (left panel), primary breast tumor tissue (middle panel) and recurrence breast tumor tissue (right panel). For immunohistochemical analysis, the scores were determined by combining the proportion of positively stained tumor cells and the intensity of staining, giving rise to a Staining Index (SI) value for each sample. The proportion of positively stained tumor cells was graded as follows: $0(<5 \%$ positively stained tumor cells), 1 ( $5 \%$ to $25 \%$ positive tumor cells), 2 ( $25 \%$ to $50 \%$ positive tumor cells), 3 (50\% to $75 \%$ positive tumor cells) and 4 (>75\% positive tumor cells). Representative photomicrographs were taken using a phase-contrast microscope (original magnification, $\times 200$ ). Al, aromatase inhibitor; IFITM1, interferon induced transmembrane protein1; PLSCR1, phospholipid scramblase 1; SD, standard deviation.

Normal breast tissue showed no staining for IFITM1 or PLSCR1 (SI score $=0$ ); primary tumors showed medium staining for IFITM1 and PLSCR1 which correlated with low expression (SI score of $\leq 3$ ); and AI-resistant (recurrence) tumors showed very strong staining for IFITM1 and PLSCR1 which correlated with high expression of both proteins (SI score of $\geq 6$ ). Taken together, these results demonstrate that interferon regulated genes are constitutively overexpressed in AI resistant breast cancer and they suggest that interferon signaling might be deregulated in the resistant cells.

\section{IFITM1 and PLSCR1 are localized primarily in the cytoplasm in Al-resistant cells}

Previous studies have shown that IFITM1 and PLSCR1 localize primarily in the plasma membrane [38,39]; however, these proteins can also translocate to the nucleus and bind genomic DNA. We examined the cellular 
Table 1 Staining intensity of IFITM1 and PLSCR1 expression in normal and breast tumor tissues

\begin{tabular}{llcc}
\hline Tissue Type & $\begin{array}{l}\text { Staining } \\
\text { Intensity }\end{array}$ & IFITM1 & PLSCR1 \\
\hline Normal tissues & No stain & $10 / 10$ & $9 / 10$ \\
& Weak & $0 / 10$ & $1 / 10$ \\
& Strong & $0 / 10$ & $0 / 10$ \\
Primary tumors & No stain & $32 / 40$ & $32 / 40$ \\
& Weak & $8 / 40$ & $8 / 40$ \\
Recurrence tumors & Strong & $0 / 40$ & $0 / 40$ \\
& No stain & $0 / 40$ & $0 / 40$ \\
& Weak & $4 / 40$ & $2 / 40$ \\
\hline Staining intensity was calculated for IFITM1 and PLSC1 expression in norma
\end{tabular}

Staining intensity was calculated for IFITM1 and PLSCR1 expression in normal breast tissue $(\mathrm{N}=10)$, primary breast tumors $(\mathrm{N}=40)$, and Al-resistant/recurrence breast tumors $(\mathrm{N}=40)$ as described in Methods. $\mathrm{Al}$, aromatase inhibitor; IFITM1,

interferon induced transmembrane protein1; PLSCR1, phospholipid scramblase 1.

localization of IFITM1 and PLSCR1 in AI-resistant MCF-7:5C cells and AI-sensitive MCF-7 cells using immunofluorescence (IF). Our results showed that IFITM1 (Figure 2A) and PLSCR1 (Figure 2B) were highly expressed in resistant MCF-7:5C cells compared to parental MCF-7 cells and that both proteins localized primarily in the cytoplasm with minor nuclear localization. Western blot analysis of fractionated MCF-7 and MCF-7:5C cells confirmed that IFITM1 and PLSCR1 were overexpressed in MCF-7:5C cells compared with MCF-7 cells and that both proteins were localized primarily in the cytoplasm with some nuclear localization observed for IFITM1 (Figure 2C).

\section{IFNa drives overexpression of IFITM1 and PLSCR1 in}

Al-resistant MCF-7:5C cells

Binding of interferon alpha (IFN $\alpha$ ) to the IFN alpha Type 1 receptor (IFNAR1) complex initiates a signaling cascade comprising phosphorylation and dimerization of STAT1/2 molecules followed by their translocation to the nucleus, where they regulate the expression of ISGs. To investigate whether constitutive overexpression of IFITM1 and PLSCR1 in resistant MCF-7:5C cells is driven by the canonical IFN $\alpha$ signaling pathway, we first measured intracellular IFN $\alpha$ level in the supernatant and lysate of AI-resistant MCF-7:5C and parental MCF-7 cells using ELISA. As shown in Figure $3 \mathrm{~A}$, IFN $\alpha$ protein level was significantly higher in the supernatant and lysate of resistant MCF-7:5C cells compared to parental MCF-7 cells. IFN $\alpha$ mRNA expression was also significantly elevated in resistant MCF-7:5C cells compared to MCF-7 cells (Figure 3B). Next, we used a neutralizing antibody against the type 1 interferon receptor, IFNAR1/ 2 , to see whether blocking the receptor reduces IFITM1

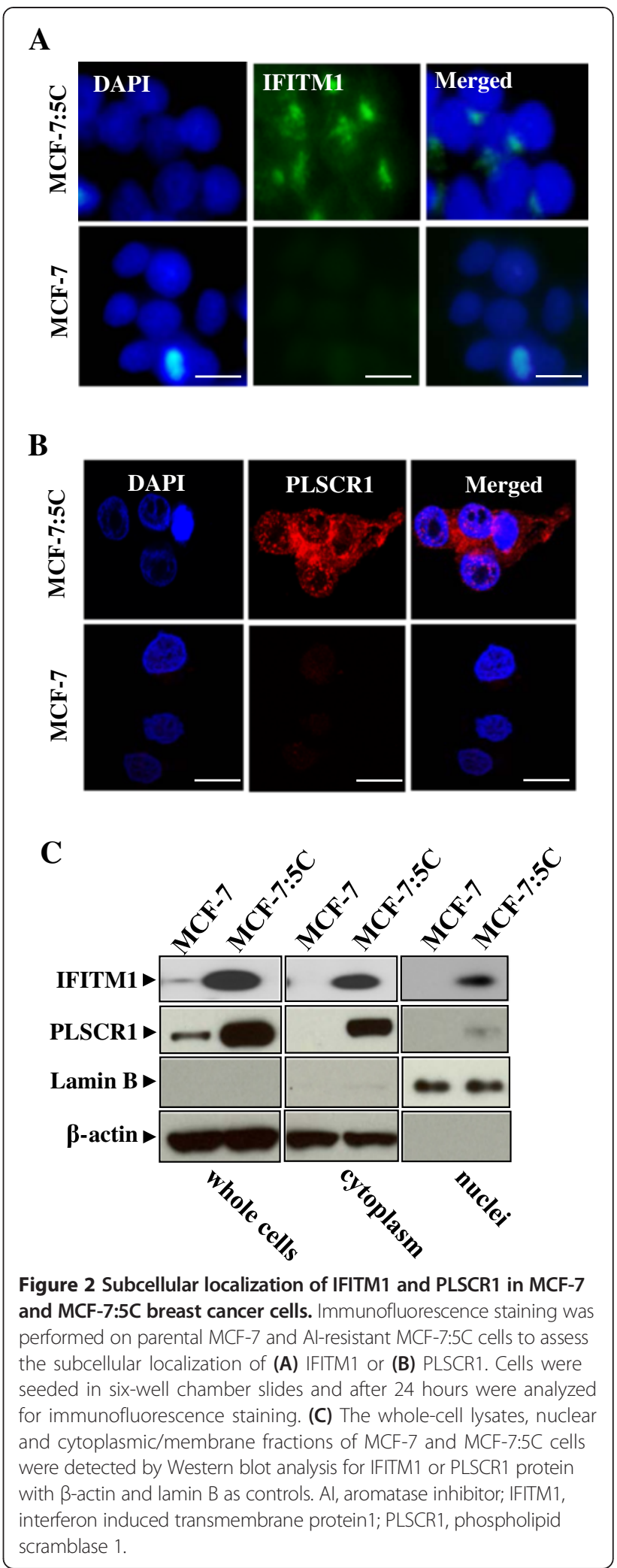

and PLSCR1 expression in the resistant cells. As shown in Figure $3 \mathrm{C}$, the IFNAR1/2 neutralizing antibody, $\alpha-$ IFNAR-Ab, markedly reduced the basal expression of 


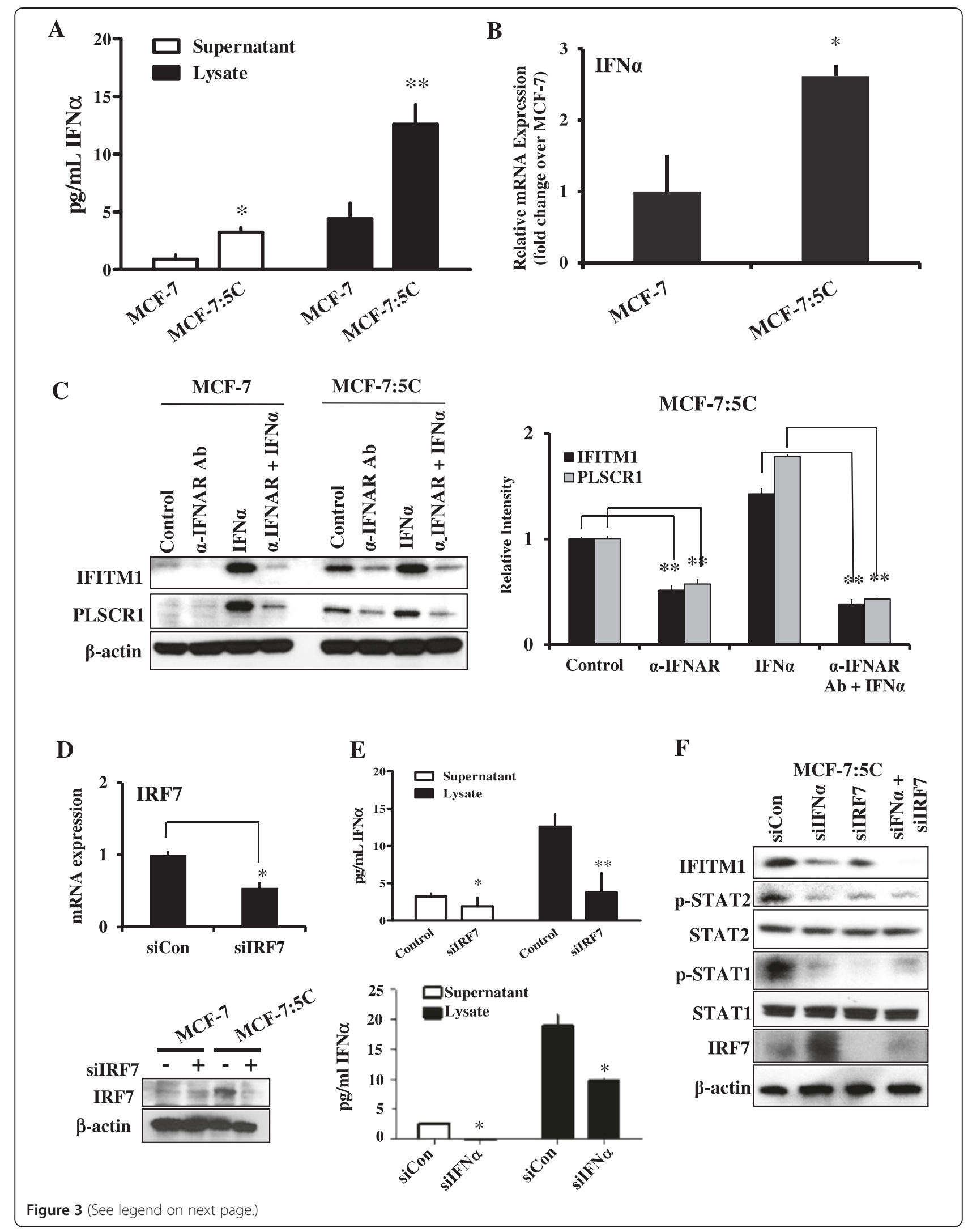


(See figure on previous page.)

Figure 3 Elevated level of intracellular IFNa drives constitutive overexpression of IFITM1. (A) ELISA analysis of baseline expression of IFNa in cell lysates and supernatant in MCF-7:5C and MCF-7 cells. Cells $\left(1 \times 10^{6}\right)$ were seeded in a six-well plate in their standard culture media and after 48 hours cells were harvested and the supernatant and pellets were collected. Cell pellets were then lysed by sonication in RIPA buffer containing protease inhibitors. IFNa was measured in the supernatants and cell lysates by ELISA as described in Methods. All the illustrated data were performed in duplicate and are expressed as mean values of three independent experiments \pm SD. (B) Measurement of IFNa mRNA was determined by real-time PCR. Fold change was calculated by means of the $\Delta \Delta C T$ method using PUM1 as an internal control. Values are displayed as relative to MCF-7 cells and are means of triplicate measurements \pm SD in three independent experiments. (C) Blockade of type 1 interferon receptor, IFNAR1, using neutralizing antibody MAB1155, in MCF-7 and MCF-7:5C cells. Cells were pretreated with $5 \mu \mathrm{g} / \mathrm{mL}$ anti-IFNAR1/2 for 4 hours and then treated with $20 \mathrm{U} / \mathrm{mL}$ human recombinant IFNa for 24 hours. Cells were analyzed by Western blot to assess IFITM1, PLSCR1 and $\beta$-actin protein level. Results shown are representative of three independent experiments. The protein levels were quantified using the ImageJ software (downloaded from NIH website [40]) and normalized as the ratio related to $\beta$-actin. ${ }^{*} P<0.05$ or ${ }^{* *} P<0.01$ versus control. (D) siRNA knockdown of IRF-7 expression in MCF-7:5C cells. Cells were transiently transfected with siRNA targeting IRF-7 and after 24 hours knockdown was verified at the mRNA and protein level via RT-PCR and Western blot analyses. (E) Effect of IRF-7 knockdown on IFNa expression in resistant MCF-7:5C cells. Cells were transiently transfected with siRNA targeting IRF-7. After 24 hours, IFNa mRNA and IFNa protein expression were determined by real-time PCR and ELISA, respectively. Data shown for RT-PCR is expressed as fold change over cells transfected with control siRNA. Values are displayed as means \pm SD of three independent experiments performed in triplicate. ${ }^{*} P<0.05$ or ${ }^{* *} P<0.01$. (F) The effect of IFNa or IRF-7 knockdown on IFITM1, p-STAT2, STAT2, p-STAT1, STAT1, and IRF-7 protein expression in resistant MCF-7:5C cells. Cells were transiently transfected with silFNa, silRF-7 or siCon for 48 hours and Western blot analysis was performed on lysates. Results shown are representative of two independent experiments IFITM1, interferon induced transmembrane protein1; IFNAR1, IFN alpha Type 1 receptor; NIH, National Institutes of Health; PLSCR1, phospholipid scramblase 1; SD, standard deviation.

IFITM1 and PLSCR1 in resistant MCF-7:5C cells and it completely blocked exogenous IFN $\alpha$ induction of IFITM1 and PLSCR1 in parental MCF-7 cells. We further tested whether suppression of the intracellular IFNa level is capable of reducing IFITM1 and PLSCR1 expression in the resistant cells. Induction of IFNa production is primarily controlled at the transcription level by the transcription factor IRF-7, hence, we performed siRNA knockdown of IRF-7 to suppress intracellular IFN $\alpha$ level in the resistant cells. We should note that IRF-7 mRNA (Additional file 1: Figure S1) and IRF-7 protein (Figure 3D, bottom panel) were constitutively overexpressed in resistant MCF-7:5C cells compared to parental MCF-7 cells. As shown in Figure 3D, siIRF-7 markedly reduced IRF-7 mRNA and protein expression in resistant MCF-7:5C cells and it significantly decreased IFN $\alpha$ protein (Figure $3 \mathrm{E}$, top) and IFN $\alpha$ mRNA level (data not shown) in these cells. In addition, we found that siRNA knockdown of IFN $\alpha$ reduced its protein level in the supernatant by $100 \%$ and in the lysate by $50 \%$ (Figure 3E, bottom). Furthermore, we found that siRNA knockdown of both IFN $\alpha$ and IRF-7 completely reduced IFITM1, PLSCR1, p-STAT1 and p-STAT2 protein expression in the resistant cells (Figure 3F). Taken together, these data indicate that IFN $\alpha$ is significantly elevated in the supernatant and lysate of AIresistant MCF-7:5C breast cancer cells and that activation of the canonical IFN $/$ IFNAR signaling pathway plays a critical role in driving the constitutive overexpression of IFITM1 and other ISGs in the resistant cells.

\section{Dysregulation of type $1 \mathrm{IFNa}$ signaling in Al-resistant MCF-7:5C cells}

Since IFITM1 and PLSCR1 were constitutively overexpressed in the resistant cells, we wanted to assess the functional integrity of the interferon signaling pathway in the resistant cells compared to parental MCF-7 cells. Cells were treated with $1,000 \mathrm{U} / \mathrm{ml}$ of IFN $\alpha$ for 0 to 24 hours and protein levels of IFITM1, PLSCR1, STAT1, p-STAT1 (Y701), STAT2, p-STAT2 (Tyr690) and IFNAR1 were determined by Western blot analysis. We found that in parental MCF-7 cells, IFN $\alpha$ treatment significantly increased PLSCR1, IFITM1, STAT1, p-STAT1, STAT2, p-STAT2 and IFNAR1 protein expression in a time-dependent manner with maximum induction of PLSCR1, IFITM1, STAT1, STAT2 and IFNAR1 observed at 24 hours and for p-STAT1 and p-STAT2 at 30 minutes (Figure 4A, left panel). In contrast, we found that IFITM1 and PLSCR1 were constitutively overexpressed in resistant MCF-7:5C cells and that treatment with exogenous IFN $\alpha$ only increased p-STAT and p-STAT2 protein; however, it did not further increase the level of IFITM1, PLSCR1 or STAT1 at any of the time points except at 24 hours where we detected a $<2$-fold increase in PLSCR1 and IFITM1 (Figure 4A, right panel; Additional file 2: Figure S2). A similar trend was observed at the mRNA level for IFITM1, PLSCR1 and STAT1 in resistant MCF-7:5C cells compared to parental MCF-7 cells (Additional file 3: Figure S3). In MCF-7 cells, exogenous IFN $\alpha$ induced IFITM1 mRNA by approximately 374 -fold, PLSCR1 mRNA by approximately 9-fold and STAT1 mRNA by approximately 11-fold at 48 hours, whereas, in resistant MCF-7:5C cells, treatment with IFN- $\alpha$ induced IFITM1 mRNA by approximately 3fold, PLSCR1 mRNA by approximately 2-fold, and STAT1 mRNA by approximately 2-fold (Additional file 3: Figure S3). These findings suggest that IFITM1, PLSCR1 and STAT1 are constitutively overexpressed in the resistant cells due to dysregulation of interferon signaling, whereas, in parental MCF-7 cells, the interferon signaling pathway 


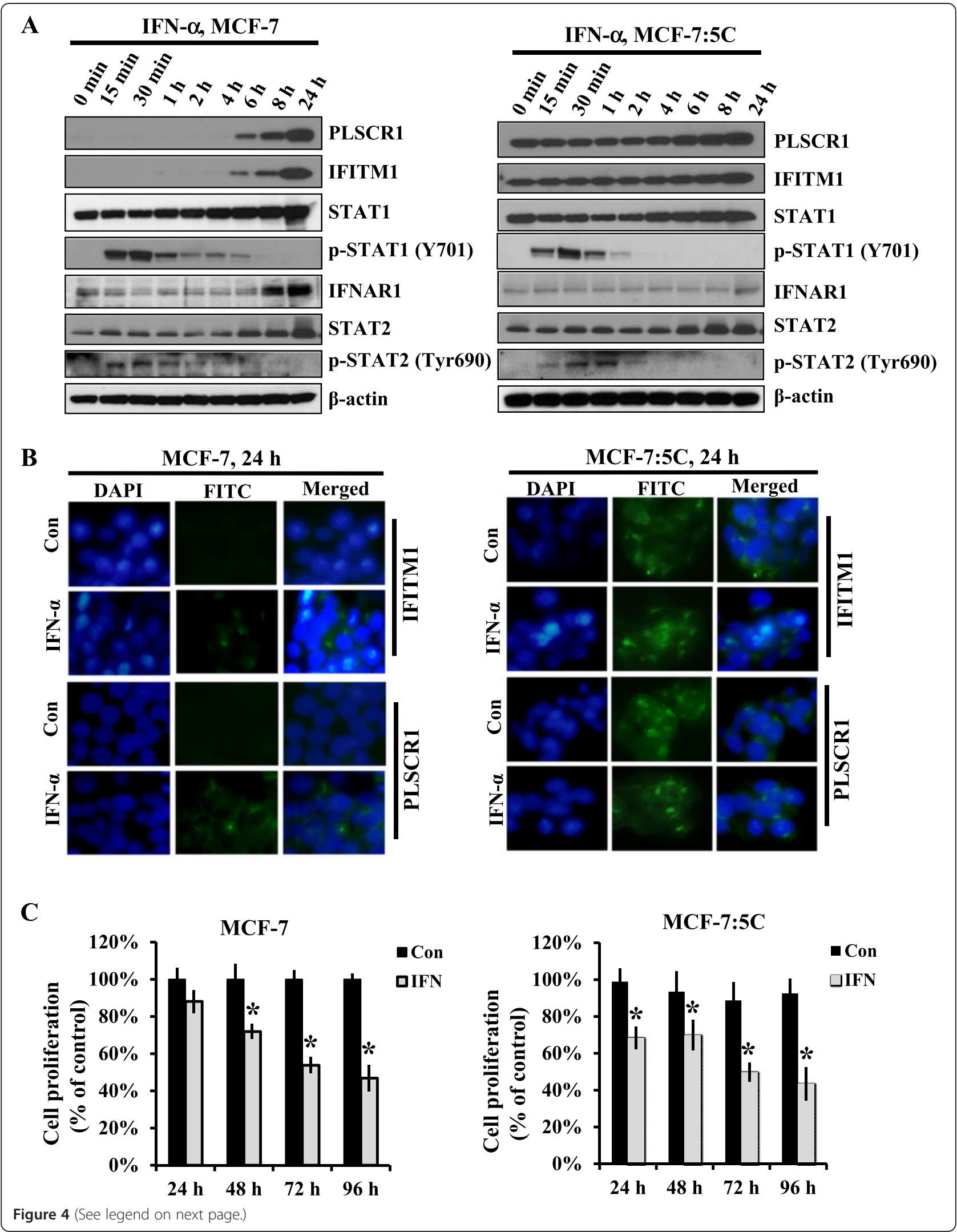


(See figure on previous page.)

Figure 4 Activation of interferon signaling pathway in parental MCF-7 and Al-resistant MCF-7:5C cells in response to INFa. (A) MCF-7 (left panel) and MCF-7:5C (right panel) cells were incubated with IFNa (1000 U/ml) for the indicated time points. The cell extracts were examined by Western blotting using anti-PLSCR1, anti-IFITM1, anti-STAT1, anti-phospho-STAT1 (Y701), anti-IFNAR1, anti-STAT2, anti-phospho-STAT2 (Tyr690) and anti- $\beta$-actin. (B) Cellular localization of IFITM1 and PLSCR1 in MCF-7 and MCF-7:5C cells following IFNa treatment. Cells were treated for 24 hours with IFNa $(1000 \mathrm{U} / \mathrm{ml})$ and then analyzed for immunofluorescence staining of IFITM1 and PLSCR1 (original magnification 200x). (C) MCF-7 and MCF-7:5C cells were treated with IFNa $(1000 \mathrm{U} / \mathrm{ml})$ for 24, 48, 72 and 96 hours and cell proliferation was measured by the MTT assay. All the illustrated data are expressed as mean values of three independent experiments. Standard deviations are shown. ${ }^{*} P<0.05$; ${ }^{*} P<0.01$. Al, aromatase inhibitor; IFITM1, interferon induced transmembrane protein1; IFNAR1, IFN alpha Type 1 receptor; MTT, 3-(4,5-dimethylthiazol-2-YI)-2,5-diphenyltetrazolium bromide; PLSCR1, phospholipid scramblase 1; STAT1,2, Signal transducer and activator of transcription 1,2.

is functionally intact and the induction of IFITM1 and other ISGs is tightly controlled.

Next, we examined whether IFN $\alpha$ treatment facilitated translocation of IFITM1 and PLSCR1 from the cytoplasm to the nucleus. As shown in Figure 4B, treatment with IFN $\alpha$ significantly increased IFITM1 and PLSCR1 protein expression in MCF-7 cells but not in AIresistant MCF-7:5C cells; however, it did not cause IFITM1 or PLSCR1 to translocate from the cytoplasm to the nucleus in either cell line. Interestingly, cell viability assay showed that IFN $\alpha$ treatment significantly inhibited the proliferation of both MCF-7 and MCF-7:5C cells in a time-dependent manner (Figure 4C) and that AIresistant MCF-7:5C cells were slightly more sensitive to the growth inhibitory effect of IFN $\alpha$ than MCF-7 cells.

\section{Knockdown of IFITM1 induces cell death in Al-resistant MCF-7:5C breast cancer cells}

Previous studies have reported that IFITM1 and PLSCR1 exert both antiproliferative and proliferative effects in different types of cancer cells; however, their functional significance in AI-resistant breast cancer cells is not known. To determine the functional significance of IFITM1 and PLSCR1 in AI-resistant MCF-7:5C breast cancer cells, we transiently transfected MCF-7:5C cells with siRNA targeting IFITM1 or PLSCR1 and we assessed the effect of their knockdown on cell proliferation, cell death and cell cycle progression. Western blot analysis confirmed knockdown of IFITM1 and PLSCR1 protein in AI-resistant MCF-7:5C cells at 24, 48 and 72 hours post-transfection (Figure 5A). Cell viability assay showed that knockdown of IFITM1, but not PLSCR1, significantly inhibited the proliferation of AIresistant MCF-7:5C cells at 72 hours relative to control cells and it markedly enhanced the inhibitory effect of $E_{2}$ in these cells (Figure 5B). The growth inhibitory effect of IFITM1-knockdown in AI-resistant MCF-7:5C cells was due to cell death, as demonstrated by annexin V-PI staining (Figure 5C). Specifically, knockdown of IFITM1 in MCF-7:5C cells increased the total number of dead cells from $10.8 \%$ (siCon) to $35.1 \%$ in the IFITM1knockdown cells and it enhanced the apoptotic effect of $\mathrm{E}_{2}$ from $34.6 \%$ to $57.1 \%$ (Figure $5 \mathrm{C}$ ). We should note that the ability of $E_{2}$ to induce cell death in AI-resistant breast cancer cells has previously been reported by our laboratory $[11,15,16]$; however, this is the first study to show that suppression of IFITM1 enhances $E_{2}$-induced cell death in AI resistant breast cancer cells. Further analysis indicated that knockdown of IFITM1 significantly increased the expression of p21, Bax and Noxa in AI-resistant MCF-7:5C cells; however, it did not significantly alter p53 expression in these cells (Figure 5D). To validate the specificity and the biological function of IFITM1 in our resistant cells we used a second shRNA targeting IFITM1 (Additional file 4: Figure S4). We found that shRNA knockdown of IFITM1 induced poly ADP ribose polymerase (PARP) cleavage (Additional file 4: Figure S4A), reduced cell proliferation (Additional file 4: Figure S4B) and induced cell death in resistant MCF-7:5C cells which was further enhanced by the addition of $E_{2}$ (Additional file 4: Figure S4C). To confirm that IFN $\alpha$ was responsible for the dysregulation of IFITM1 and that blocking its function enhances $\mathrm{E}_{2}$-induced cell death, we knockeddown IFN $\alpha$ expression in resistant MCF-7:5C cells and then treated the cells with $E_{2}$ for an additional 96 hours. As shown in Additional file 5: Figure S5, knockdown of IFN $\alpha$ significantly reduced the proliferation of MCF-7:5C cells and it significantly enhanced $E_{2}$-induced death in these cells at 96 hours. Furthermore, we found that blocking IFNAR1/2 with a neutralizing antibody also reduced the proliferation of MCF-7:5C cells and it markedly enhanced $\mathrm{E}_{2}$-induced death in these cells at the same time point. These findings confirm that IFN $\alpha$ is responsible for the dysregulated expression of IFITM1 in the resistant cells and that blocking its function collaborates with E2 to enhance cell death in these cells. Furthermore, these findings suggest that IFITM1 overexpression provides a survival advantage to the resistant cells that allows them to grow in an estrogen-depleted environment and that knockdown of IFITM1 disrupts the survival pathway in these cells thus sensitizing them to cell death.

\section{IFITM1 knockdown inhibits migration and invasion of Al-resistant MCF-7:5C cells}

There is evidence that IFITM1 overexpression induces tumor resistance to natural killer (NK) cells in gastric 
A
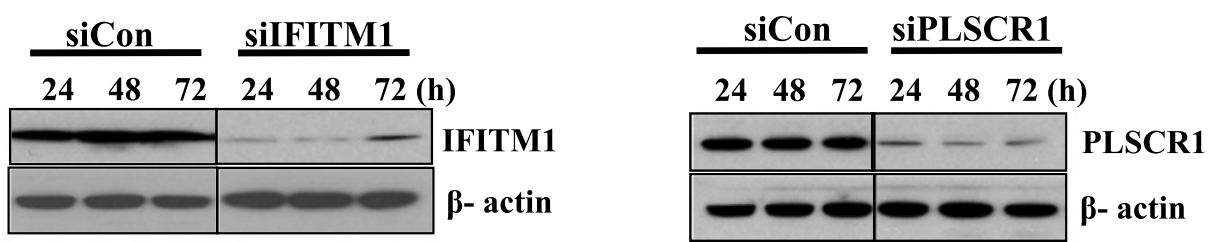

B
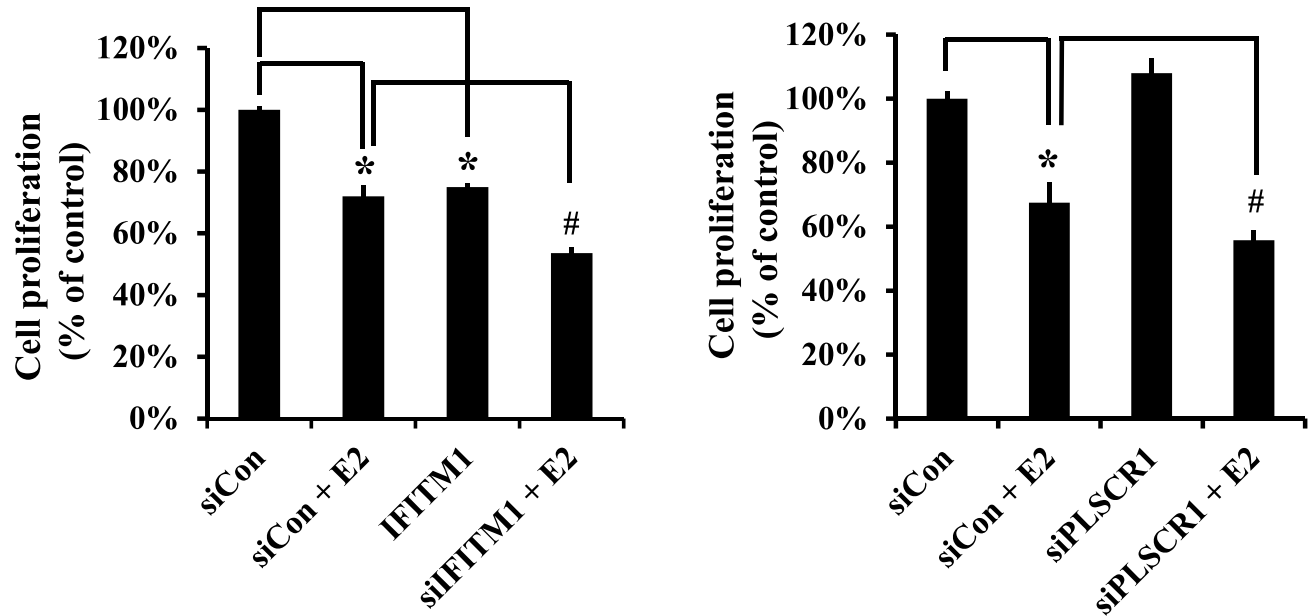

C

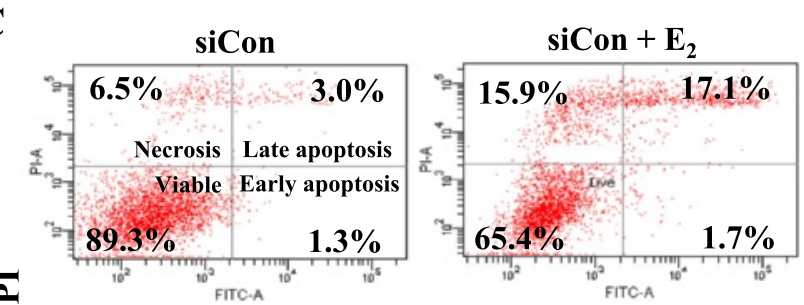

D
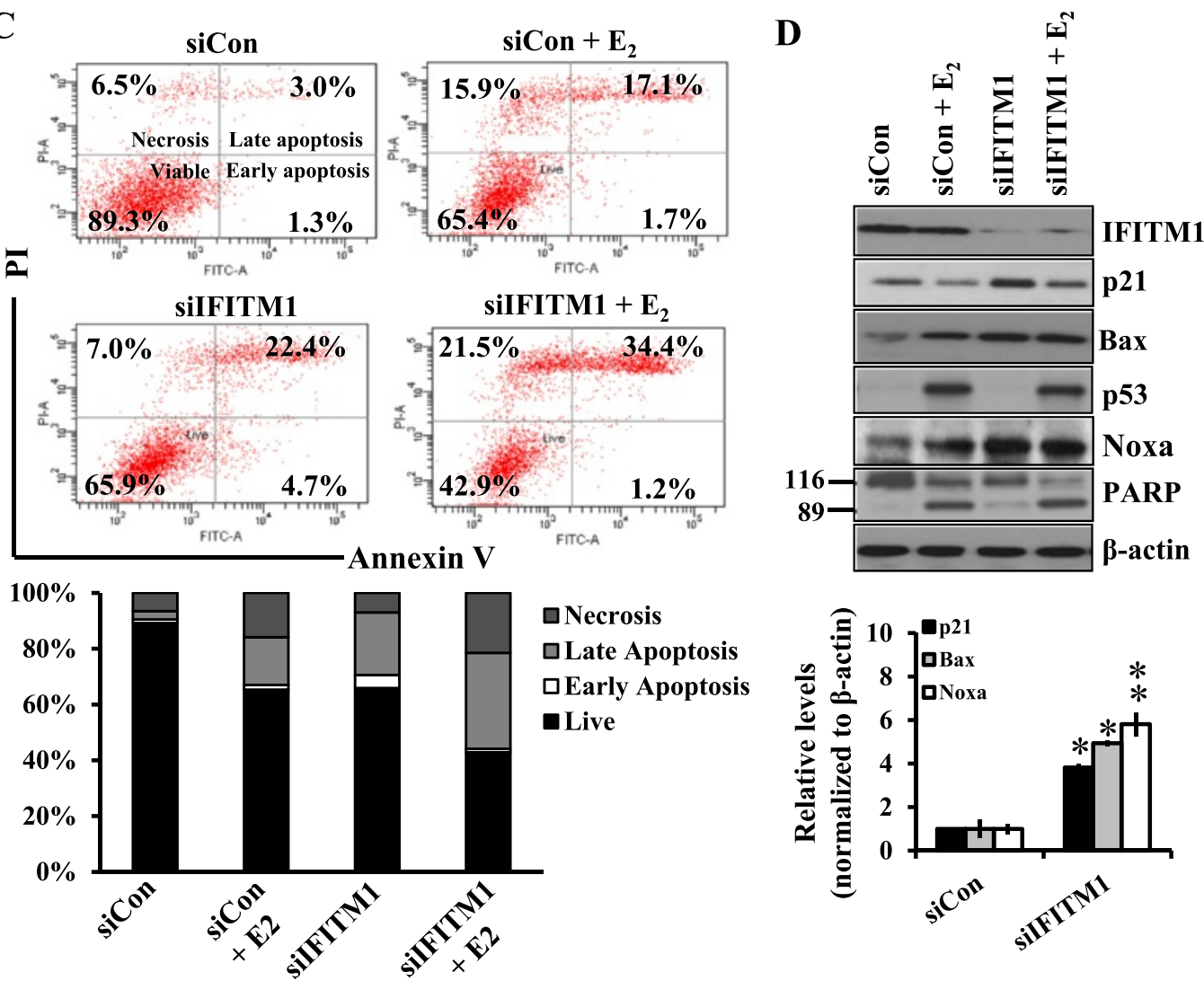

口Necrosis

口Late Apoptosis 口Early Apoptosis

- Live

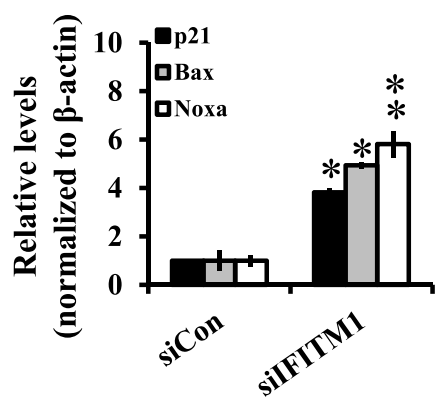

Figure $\mathbf{5}$ (See legend on next page.) 
(See figure on previous page.)

Figure 5 IFITM1 knockdown increases cell death in Al-resistant breast cancer cells. (A) MCF-7:5C cells were transfected with control siRNA (siCon), IFITM1 siRNA (silFITM1) or PLSCR1 siRNA (siPLSCR1) for 24, 48 and 72 hours and cell extracts were subject to Western blotting analysis to assess IFITM1 and PLSCR1 protein expression. (B) MCF-7:5C cells were transfected with siCon, silFITM1 (left panel) or siPLSCR1 (right panel) for 24 hours and then treated with $1 \mathrm{nM} \mathrm{E}_{2}$ for an additional 72 hours. Cell proliferation was measured by the MTT assay. All the illustrated data are expressed as mean values of three independent experiments. Standard deviations are shown. ${ }^{*} P<0.05$ versus control; $\# P<0.05$ versus $E_{2}$ treatment. (C) MCF-7:5C cells were transfected with siCon or silFITM1 and after 24 hours were exposed to $E_{2}(1 \mathrm{nM})$ for an additional 96 hours. Cells were then stained with annexin V-FITC and PI for detection of apoptosis as described in Methods. (D) Cells were treated as described above in (C) and were analyzed by Western blotting to assess IFITM1, p21, Bax, p53, Noxa and PARP protein expression. Membranes were stripped and reprobed for $\beta$-actin, which was used as a loading control. The protein levels for p21, Bax and Noxa were quantified using the ImageJ software (downloaded from the $\mathrm{NIH}$ website) and normalized as the ratio relate to $\beta$-actin. ${ }^{*} P<0.05$; ${ }^{*} P<0.01$. Al, aromatase inhibitor; $\mathrm{E}_{2}, 17 \beta$-estradiol; FITC, fluorescein isothiocyanate; IFITM1, interferon induced transmembrane protein1; IFNAR1, IFN alpha Type 1 receptor; MTT, 3-(4,5-dimethylthiazol-2-Yl)-2,5-diphenyltetrazolium bromide; $\mathrm{NIH}$, National Institutes of Health; PARP, poly ADP ribose polymerase; PI, propidium iodide; PLSCR1, phospholipid scramblase 1.

tumor cells and it facilitates migration and invasion of gastric cancer cells [29]. In addition, overexpression of IFITM1 has been shown to promote head and neck tumor invasion by mediating the expression of matrix metalloproteinases 12 and 13 [32]. To investigate the role of IFITM1 in breast cancer progression, we examined the influence of IFITM1 knockdown on migration and invasion of AI-resistant MCF-7:5C breast cancer cells. Western blot and real-time PCR analysis confirmed that IFITM1 protein and mRNA expression suppressed by siRNA in MCF-7:5C cells compared with siCon-transfected cells (Figure 6A). Silencing of IFITM1 markedly reduced the migratory ability (Figure 6B) and invasion capacity (Figure 6C) of AI-resistant MCF-7:5C cells. The cell migration and invasion counted from 10 randomly selected areas per well at 24 hours showed that siRNA knockdown of IFITM1 inhibited migration by $54 \%$ (Figure $6 \mathrm{~B}$, bar graph) and invasion by approximately $78 \%$ (Figure 6C) compared with siCon-transfected cells. To confirm that the inhibitory effect of IFITM1 knockdown on migration and invasion was not due to cell death we measured apoptosis (via flow cytometry) and cell viability in IFITM1-knockdown MCF-7:5C cells at the same time point (24 hours) the migration and invasion assays were performed. As shown in Figure 6D, IFITM1 knockdown did not induce cell death (top panel) or reduce cell viability (bottom panel) at 24 hours; hence, its inhibitory effect on migration and invasion at 24 hours is not due to cell death. However, we should note that knockdown of IFITM1 does cause significant cell death at 72 hours; hence, migration and invasion would be inhibited at the later time points due to cell death. This result suggests that overexpression of IFITM1 enhances the ability of AI-resistant MCF-7:5C cells to migrate and invade and its suppression has the opposite effect.

\section{STAT1 and STAT2 regulate IFITM1 and PLSCR1 expression in resistant MCF-7:5C cells}

STAT1 and STAT2 are members of the signal transducers and activators of transcription family of transcription factors that play a pivotal role in regulating type $I(\alpha / \beta)$ and type II $(\gamma)$ interferon signaling. In response to either IFN $\alpha$ or IFN $\beta$ stimulation, STAT1 and STAT2 form homodimers or heterodimers, move to the nucleus and activate the transcription of interferon response genes. Since IFITM1 and PLSCR1 are constitutively overexpressed in AI-resistant MCF-7:5C cells, we examined whether knockdown of STAT1 or STAT2 is capable of altering their expression in MCF-7:5C cells. AI-resistant MCF-7:5C cells were transiently transfected with control siRNA (siCon), STAT1 siRNA (siSTAT1) or STAT2 siRNA (siSTAT2) and the effect of knockdown on IFITM1 and PLSCR1 expression was assessed at 24 and 48 hours using Western blot analysis. As shown in Figure 7A (left panel), knockdown of STAT1 markedly reduced IFITM1 and PLSCR1 protein expression in resistant MCF-7:5C cells at 24 and 48 hours, and it significantly reduced the proliferation of MCF-7:5C cells, and it further enhanced the inhibitory effect of $E_{2}$ in these cells. STAT2 knockdown also reduced IFITM1 and PLSCR1 protein level in MCF-7:5C cells (Figure 7B, left panel), and it significantly enhanced the inhibitory effect of $\mathrm{E}_{2}$ in these cells (Figure 7B, right panel). Furthermore, we found that knockdown of both STAT1 and STAT2 completely suppressed IFITM1 and PLSCR1 expression in resistant MCF-7:5C cells (Additional file 6: Figure S6), thereby confirming a critical role for STAT1 and STAT2 in the regulation of IFITM1 and PLSCR1 expression. Interestingly, we found that knockdown of proapoptotic Bax and Noxa enhanced IFITM1 and PLSCR1 expression in MCF-7:5C cells, however, the mechanism by which this occurs is currently not known (Figure 7C).

\section{4-Hydroxytamoxifen inhibits IFITM1 expression in Al-resistant MCF-7:5C cells}

Since knockdown of IFITM1 significantly enhanced $E_{2}-$ induced cell death in AI-resistant MCF-7:5C cells, we next determined whether IFITM1 expression is regulated by the estrogen receptor $(E R \alpha)$. MCF-7:5C cells were treated with $1 \mathrm{nM} \mathrm{E}_{2}, 1 \mu \mathrm{M}$ of 4-hydroxytamoxifen 
A

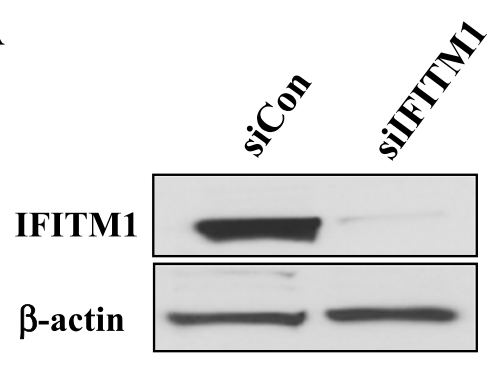

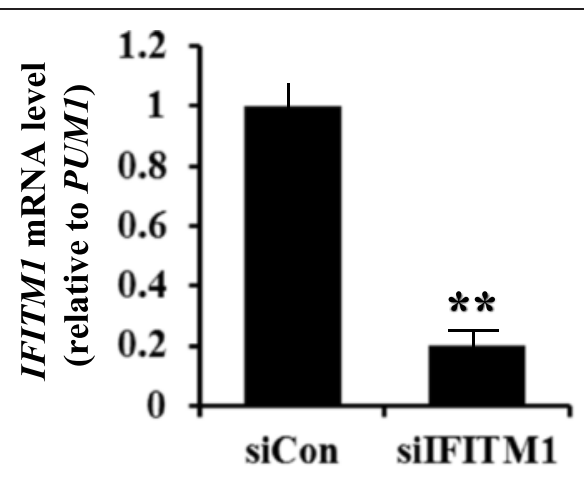

B
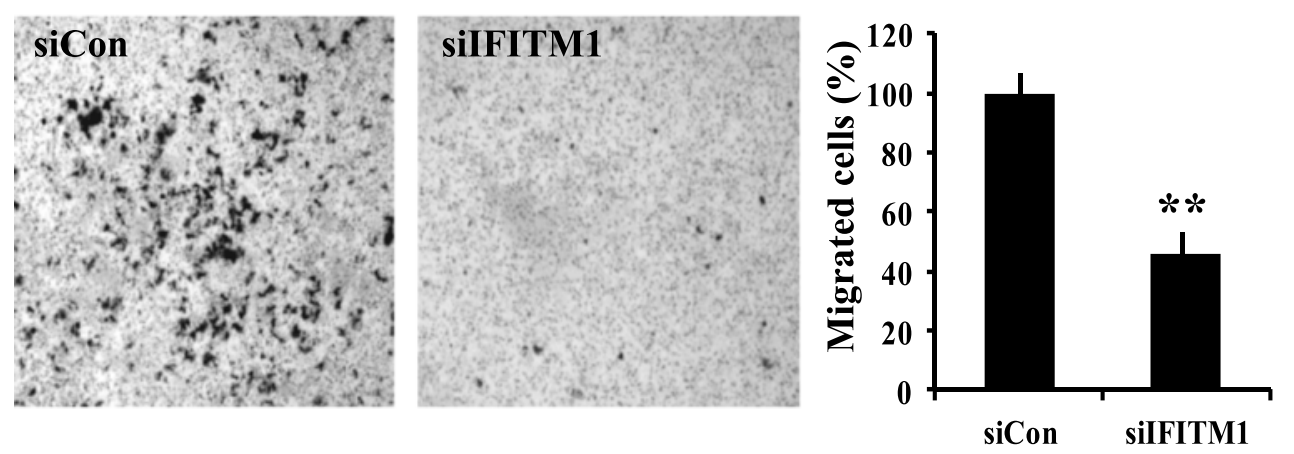

C

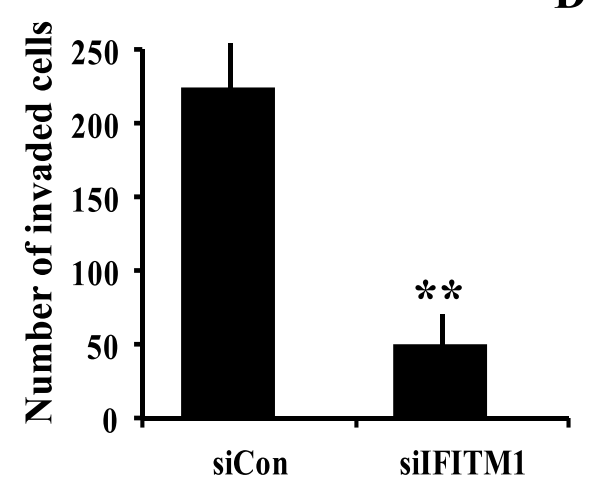

D
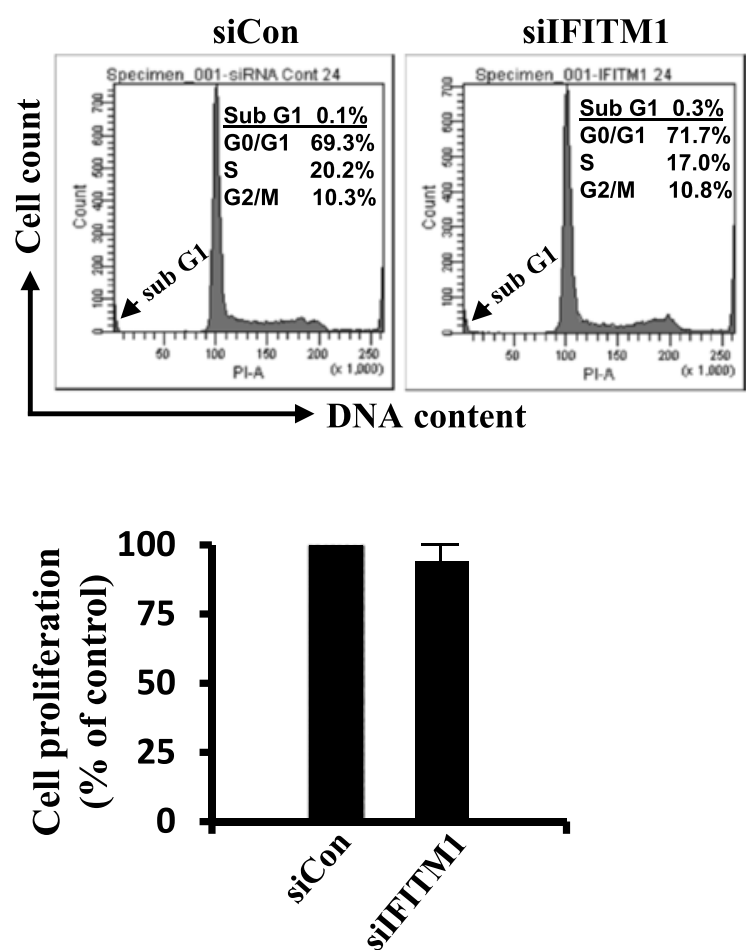
(See figure on previous page.)

Figure 6 IFITM1 knockdown decreases migration and invasion in Al-resistant MCF-7:5C breast cancer cells. (A) MCF-7:5C cells were transfected with control siRNA (siCon) or IFITM1 siRNA (silFITM1) for 24 hours and knockdown of IFITM1 protein expression was confirmed by Western blot (right panel) and real-time PCR analyses (left panel). Standard deviations are shown. ${ }^{* *} P<0.01$ versus siCon. (B and C) The effect of IFITM1 knockdown on cell migration (B) and invasion (C) was assessed by transwell migration assay and matrigel invasion assay. Cells that invaded through the Matrigel-coated transwells were fixed, stained, visualized by light microscopy and photographed. Quantitation of the Transwell assay is also shown (B, right panel). Ten random fields were counted per insert at 20X. ${ }^{* *} P<0.01$. (D) Effect of IFITM1 knockdown on cell viability in resistant MCF-7:5C cells. Cells were transfected with siCon or silFITM1 for 24 hours, then DNA content of cells was analyzed using flow cytometry as described in the Methods section. The arrow is sub G1 phase apoptosis. MTT assay (bottom panel) was also performed in the IFITM1-knockdown cells at 24 hours. All the illustrated data are expressed as mean values of three independent experiments. Standard deviations are shown. Al, aromatase inhibitor; IFITM1, interferon induced transmembrane protein1; MTT, 3-(4,5-dimethylthiazol-2-YI)-2,5-diphenyltetrazolium bromide.

(4OHT), the active metabolite to tamoxifen, or $1 \mu \mathrm{M}$ of fulvestrant (ICI 182,780), the pure antiestrogen that downregulates ER $\alpha$ and the expression of IFITM1, PLSCR1 and ER $\alpha$ were measured by Western blot analysis. As shown in Figure 8A, $E_{2}$ and fulvestrant completely down-regulated ER $\alpha$ protein but did not significantly alter IFITM1 or PLSCR1 expression, whereas $4 \mathrm{OHT}$ did not down-regulate ER $\alpha$ protein but it significantly reduced IFITM1 and PLSCR1 expression in the resistant cells. Interestingly, we found that $4 \mathrm{OHT}$ also partially blocked the cell death effect of IFITM1knockdown in MCF-7:5C cells, as demonstrated by inhibition of PARP cleavage (Figure 8B). Thus, it is possible that IFITM1 expression might be regulated by ER $\alpha$; however; we do not rule out the possibility that $4 \mathrm{OHT}$ might be exerting an effect on IFITM1 that is independent of ER $\alpha$. Further studies are needed to understand better the mechanism by which 4OHT regulates IFITM1 and whether ER $\alpha$ is involved in the process.

\section{Discussion}

Estrogen deprivation by treatment with AIs is the most effective form of endocrine therapy for postmenopausal women with estrogen receptor-positive $(E R+)$ breast cancer. Unfortunately, the majority of patients treated with AIs eventually develop resistance. While the mechanism by which endocrine resistance occurs is still not completely known, there is evidence to suggest that dysregulation in the interferon signaling pathway might play a role in the process. Indeed, studies have reported a strong correlation between constitutive expression of ISGs and resistance to radiotherapy and chemotherapy in several types of human cancers including breast cancer, ovarian cancer, lung cancer and lymphatic leukemia [41-44]. Notably, Dunbier and coworkers [45] recently reported on the poor anti-proliferative response to AI treatment in postmenopausal patients whose tumors expressed high baseline expression of immune response genes; however, these investigators did not examine interferon signaling in AI-resistant breast tumors. In the present study, we have demonstrated that interferon signaling is dysregulated in AI-resistant breast cancer cells and AI-resistant/recurrence tumors and that several interferon response genes including; IFITM1, PLSCR1, STAT1, STAT2, IRF-7, IRF-9, IFIT1, OAS1 and MX1 are constitutively overexpressed in AI-resistant breast cancer cells. In particular, we showed that IFITM1 and PLSCR1 were overexpressed at the mRNA and protein level in AI-resistant MCF-7:5C cells compared with AI-sensitive MCF-7 and T47D cells and that suppression of IFITM1, and to a lesser extent PLSCR1, significantly inhibits the proliferation of AI-resistant MCF-7:5C cells and blocked the ability of these cells to invade and migrate. Most interestingly, we found that silencing of IFITM1, PLSCR1 and STAT1 significantly enhanced $E_{2}$-induced cell death in AI-resistant MCF-7:5C cells which was associated with induction of p21, Bax, and Noxa. Additionally, we found that constitutive overexpression of IFITM1 and PLSCR1 was driven by IFN $\alpha$ signaling through the canonical IFNAR1/2/STAT1/STAT2 signaling pathway and that knockdown of STAT1 and STAT2 and blockade of IFN $\alpha$ function dramatically suppressed IFITM1 and PLSCR1 expression in the resistant cells. To our knowledge, this is the first study to demonstrate a link between dysregulation of the interferon signaling pathway and AI resistance and it suggests that targeting IFITM1 might be an effective strategy to block cell proliferation and enhance $E_{2}$-induced cell death in AIresistant breast cancer cells.

Type I interferons (IFNs $\alpha$ and $\beta$ ) are known to drive the expression of ISGs that encode proteins that possess anti-viral, anti-proliferative, pro-apoptotic and proinflammatory functions; however, many experimental data have shown that high expression of IFN-induced genes, including STAT1 itself, promotes tumor growth, metastasis and resistance to chemotherapy and radiation $[23,44,46,47]$. Normally, IFNs induce rapid activation of STATs through phosphorylation on the C-terminal tyrosine residues (Y701 for STAT1 and Y690 for STAT2) which drives the expression of ISGs [19]. Several important negative feedback mechanisms collaborate to terminate the expression of these genes several hours after IFN stimulation; for example, expression of the potent negative regulator SOCS1 is rapidly induced by IFNs [48]. 

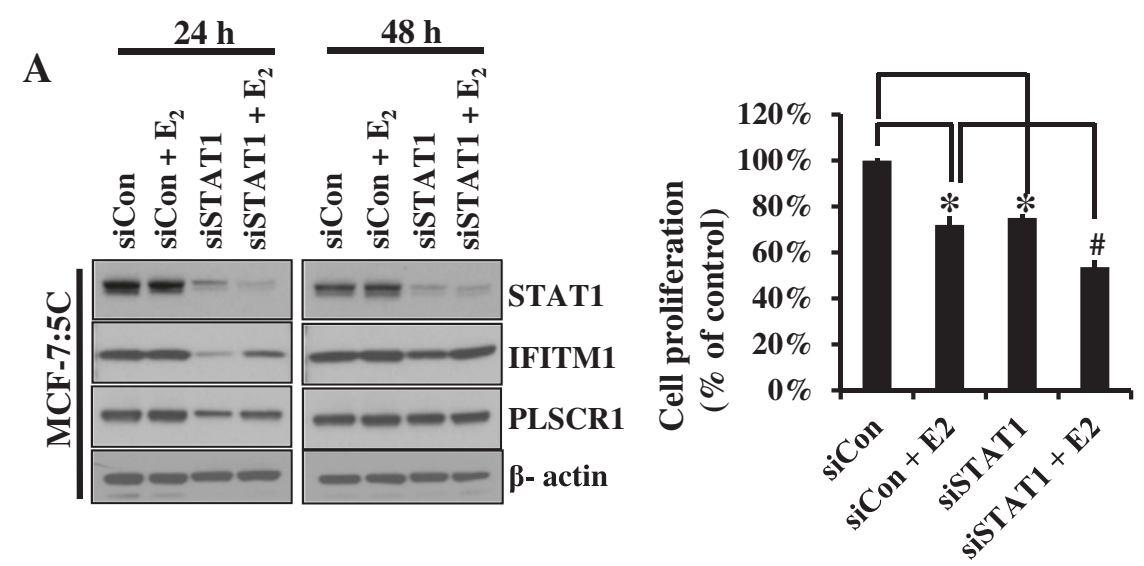

B
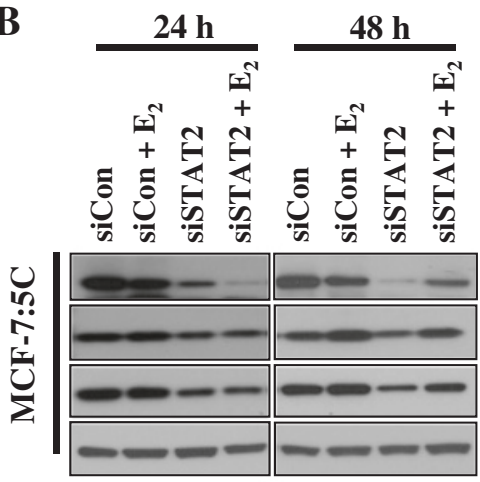

STAT2

IFITM1

PLSCR1
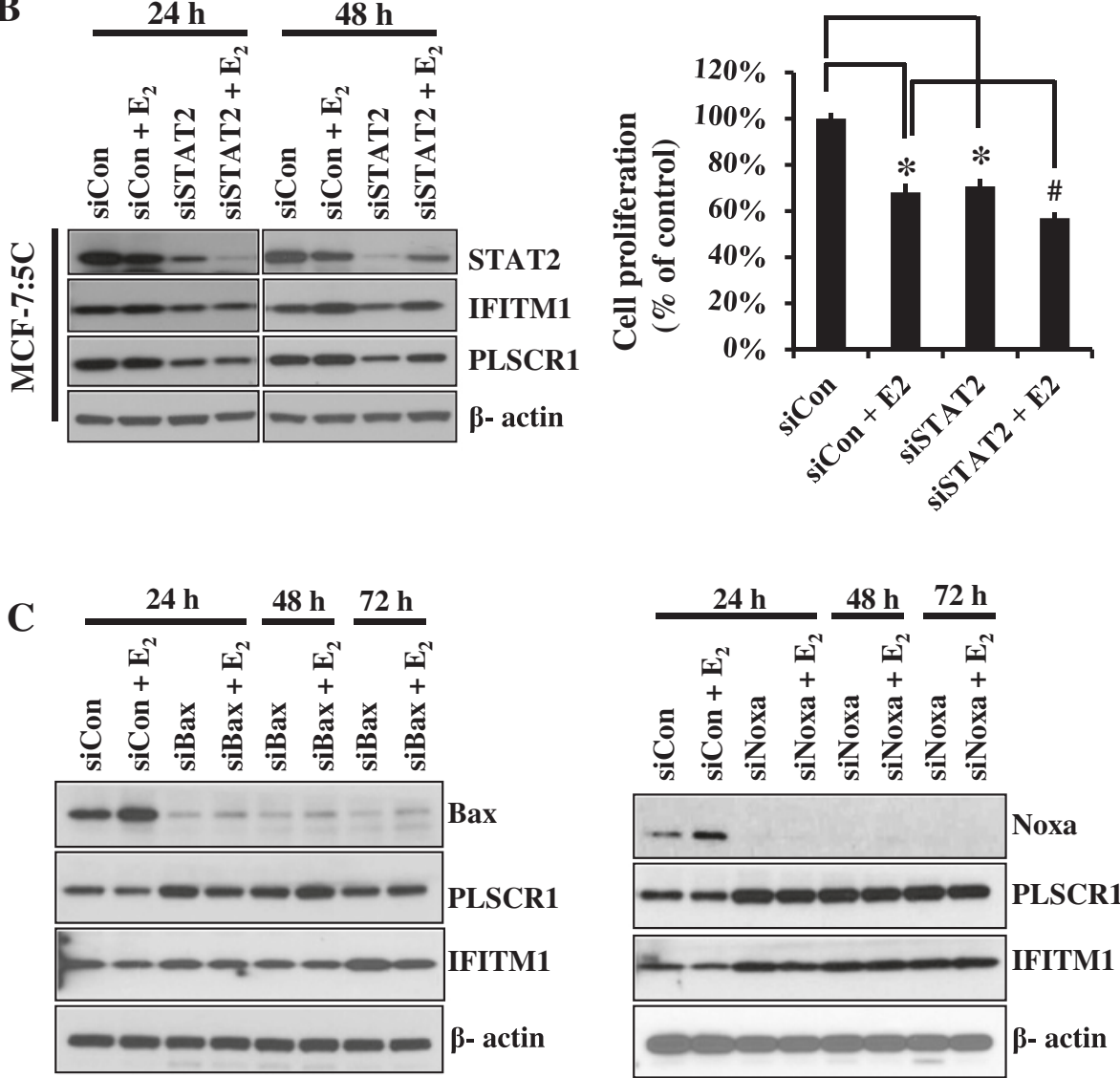

Figure 7 STAT1/STAT2 knockdown reduces IFITM1 and PLSCR1 expression. (A and B) MCF-7:5C cells were transfected with sicontrol (siCon), STAT1 siRNA (siSTAT1) or STAT2 siRNA (siSTAT2) and STAT1, STAT2, IFITM1 and PLSCR1 protein levels were assessed at 24 and 48 hours by Western blot analysis (left panels). Transfected cells were also treated with $E_{2}$ for an additional 24 and 48 hours and the above mentioned proteins were also measured (a and b, left panels). (A, B) Cell proliferation was measured in siSTAT1-knockdown and STAT2-knockdown cells in the presence or absence of $E_{2}$ by cell titer blue assay (right panels). Each value is a mean $\pm S D$ from three experiments. ${ }^{*} P<0.05$ or ${ }^{*} P<0.01$ versus the control; $\# P<0.05$ versus $E_{2}$ treatment. (C) MCF-7:5C cells were transfected with Bax siRNA (siBax) or Noxa siRNA (siNoxa) for 24 hours and then treated with $1 \mathrm{nM} \mathrm{E}$ for an additional 24, 48 or 72 hours. Cells were harvested and analyzed for Bax, PLSCR1, Noxa, and IFITM1 protein expression by Western blot. Membranes were stripped and reprobed for $\beta$-actin, which was used as a loading control. $E_{2}$, 17ß-estradiol; IFITM1, interferon induced transmembrane protein1; PLSCR1, phospholipid scramblase 1; SD, standard deviation; STAT1,2, Signal transducer and activator of transcription 1,2. 


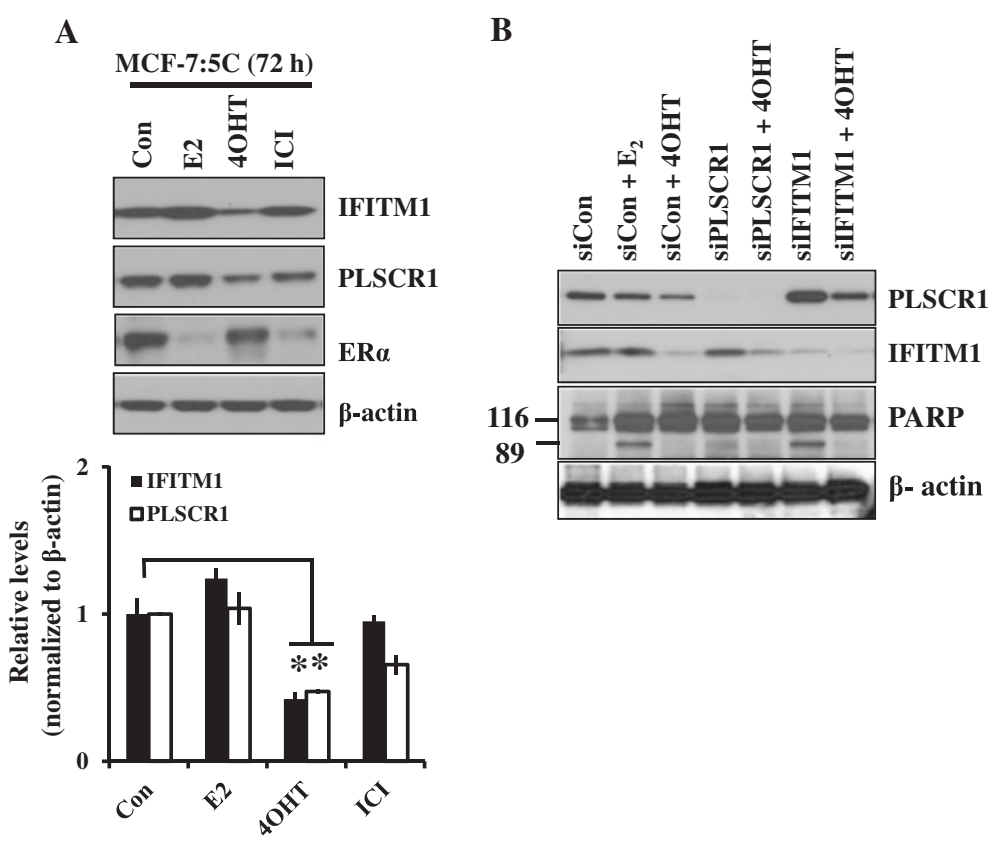

Figure 8 Tamoxifen downregulates IFITM1 and PLSCR1 expression. (A, upper panel) MCF-7:5C cells were treated with $\mathrm{E}_{2}(1 \mathrm{nM})$, 4OHT $(1 \mu \mathrm{M})$ or fulvestrant $(1 \mu \mathrm{M})$ for 72 hours. The cell extracts were examined by Western blotting using anti-PLSCR1, anti-IFITM1, anti-ERa and anti- $\beta$-actin. (A, lower panel) IFITM1 and PLSCR1 protein levels were quantified using the ImageJ software (downloaded from the NIH website) and normalized to $\beta$-actin. (B) Cells were transfected with siCon, siPLSCR1 or silFITM1 for 24 hours and then treated with $1 \mathrm{nM} \mathrm{E}_{2}$ or $1 \mu \mathrm{MM}$ 4-hydroxytamoxifen (4OHT) for an additional 24 hours. Cells were then harvested and analyzed by Western blotting to assess PLSCR1, IFITM1, PARP and $\beta$-actin protein levels. All the illustrated data are expressed as mean values of three independent experiments. Standard deviations are shown. ${ }^{*} P<0.05$ versus control; $\# P<0.05$ versus $4 \mathrm{OHT}$ treatment. $\mathrm{E}_{2}, 17 \beta$-estradiol; ERa, estrogen receptor $\mathrm{a}_{\text {; }}$ IFITM1, interferon induced transmembrane protein1; NIH, National Institutes of Health; PARP, poly ADP ribose polymerase; PLSCR1, phospholipid scramblase 1.

Based on our studies, we observed several ISGs including IFITM1, PLSCR1, IFIT1, IFI23, IRF-7, IRF-9, STAT1, STAT2, MX1 and OAS1 were overexpressed approximately 10 - to 300-fold in AI-resistant MCF-7:5C cells compared to AI-sensitive parental MCF-7 cells (Additional file 1: Figure S1). Furthermore, we found that in parental MCF-7 cells, exogenous addition of recombinant IFN $\alpha$ robustly induced the expression of IFITM1, PLSCR1 and STAT1 (10- to 200-fold) within minutes to hours, whereas,

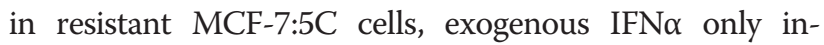
creased IFITM1, PLSCR1, and STAT1 expression by 2- to 3-fold compared to basal level (Figure 4A, Fig. S2, Fig. S3). This finding suggests that in parental MCF-7 cells, IFITM1 and other ISGs, are not expressed at the basal level unless stimulated by exogenous IFNa; however, in AI-resistant MCF-7:5C cells, IFITM1, PLSCR1 and other ISGs are constitutively overexpressed possibly due to an elevated level of IFN $\alpha$ in the cells. Notably, we detected significantly elevated levels of IFN $\alpha$ in the supernatant and lysate of AI-resistant MCF-7:5C cells compared to parental MCF-7 cells and knockdown of IFN $\alpha$ along with neutralizing antibody blockade of the receptor (IFNAR1/2) almost completely reduced IFITM1, PLSCR1, p-STAT1 and p-STAT2 expression in the resistant cells, thus suggesting a critical role for the IFN $\alpha$ canonical signaling pathway in driving the constitutive expression of the ISGs in the resistant cells. Sustained expression of ISGs and their encoded proteins was previously thought to be deleterious to cell survival [19]; however, recent studies suggest that sustained expression of a subset of ISGs and their encoded proteins might provide a survival advantage to cells [49]. We should note that ERpositive breast cancer cells are dependent on estrogen for survival and growth and when they are deprived of estrogen they tend to die. Long term, however, some breast cancer cells develop strategies to allow them to survive and grow in an estrogen-depleted environment $[10-12,15,16]$. In our working model shown in Figure 9, we propose that in AI-resistant MCF-7:5C breast cancer cells, the transcription factor IRF-7 which is a key regulator of IFN $\alpha$, is dramatically upregulated and that increased IRF-7 expression in the resistant cells stimulates the production of IFN $\alpha$ which is then secreted from the cells and binds to the IFNAR1/2STAT1/ STAT2/IRF-9 complex to induce the expression of ISGs (that is, IFITM1, PLSCR1, IFIT1, IFI21, OAS1, MX1, STAT, STAT2, IRF-7, IRF-9). Thus, it is possible that the constitutive overexpression of the ISGs provides a 


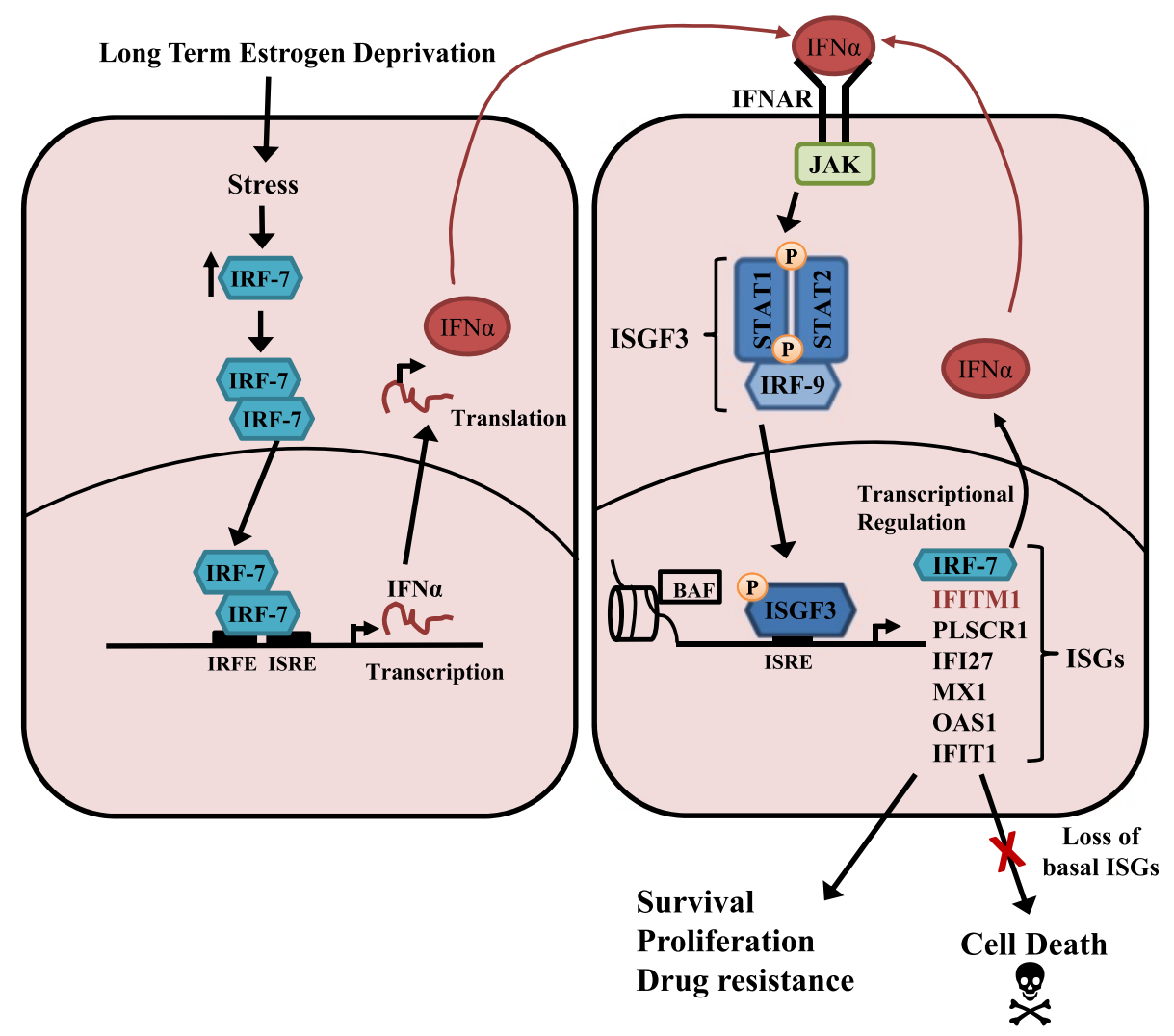

Figure 9 Schematic diagram depicting the proposed mechanism of ISG expression in Al-resistant MCF-7:5C cells. ER-positive breast cancers are dependent on estrogen for survival and growth and when these cancer cells are deprived of estrogen they tend to die. Long term, however, some breast cancer cells develop strategies to allow them to survive and grow in an estrogen-depleted environment. In our working model, we propose that long term estrogen deprivation of ERa positive breast cancer cells elicits a stress response in the cell which can possibly result in increased expression and activation of IRF-7, a known stress response gene. The activated IRF-7 enters the nucleus and binds the IFNa promoter at the IRF binding-element (IRFE) and ISRE sites, resulting in IFNa production and secretion from the cell. IFNa then binds to its cell surface receptor IFNAR1/2 which initiates JAK phosphorylation of the STAT proteins and association with IRF-9, forming the activated ISGF3 complex (p-ISGF3). The BAF complex remodels the chromatin around prospective ISGs and p-ISGF3 is imported into the nucleus where it binds to the exposed ISRE sites in ISG promoters. This results in the sustained/constitutive overexpression of numerous ISGs including IFITM1 and IRF-7, which initiates further IFNa production and thus provides autocrine cytokine signaling, reinforcing the production and accumulation of ISGs. The ISGs are pro-survival and so facilitate cell survival and proliferation under the stressful (estrogen depleted) conditions. Loss of expression of the ISGs reduces the ability of the resistant cells to survive in an estrogen-depleted environment thus causing them to die. Al, aromatase inhibitor; ER, estrogen receptor; IFITM1, interferon induced transmembrane protein1; IRF-7, IFN regulatory factor 7; ISGs, interferon stimulated genes; ISREs, IFN-stimulated response elements; JAK, Janus kinase 1 and 2; STAT, Signal transducer and activator of transcription.

survival advantage to the resistant cells that allows them to adapt and grow in an estrogen-depleted environment. The fact that knockdown of IFNa dramatically reduced IFITM1 expression in the resistant cells and its loss significantly induced cell death highlights the potential dependency of the resistant cells on elevated IFN $\alpha$ to maintain their resistant phenotype and to drive the constitutive overexpression of IFITM1 and the other ISGs in the cells. We should note that elevated IFN production has previously been reported in many pathological conditions, such as chronic inflammation and cancer, as well as in virus infections [50]. In cancers, IFN production is thought to be increased by infiltrating immune cells or by the cancer cells themselves [51].
While our studies identified a panel of ISGs that were constitutively overexpressed in our AI-resistant breast cancer cells, IFITM1 was the most functionally significant of the ISGs in the resistant cells. Clinical data indicated that IFITM1 was constitutively overexpressed in 36 out of 40 AI-resistant breast tumor samples and it was overexpressed in AI-resistant breast cancer cells approximately 20 - to 30 -fold at the mRNA and protein level. Notably, we found that knockdown of IFITM1 significantly increased cell death and it blocked invasion and migration in the resistant cells. The induction of cell death in the resistant cells following IFITM1 knockdown was associated with an increase in p21 and Bax expression; however, suppression of IFITM1 did not alter p53 
expression or cause cell cycle arrest in these cells. p21 (also known as $\mathrm{p} 21^{\mathrm{WAF1} / \mathrm{Cip} 1}$ ) is a multifunctional protein that belongs to the cip/kip family of cyclin-dependent kinase inhibitors and is known to promote G1/S or G2/ $\mathrm{M}$ cell cycle arrest and survival in a p53-dependent and p53-independent manner [52]. In addition, p21 has also been shown to play a role in apoptosis and it is suggested that its ability to regulate cell cycle arrest versus apoptosis is influenced by its cellular localization; nucleus accumulation promotes cell cycle arrest whereas cytoplasmic accumulation inhibits apoptosis [53,54]. Notably, suppression of IFITM1 also induced Bax and Noxa which are important regulators of mitochondrialmediated cell death. Interestingly, previous studies have reported that p21 counteracts mitochondrial-mediated apoptosis that relies on Bax and its upstream effector Puma [55]; however, in our study, p21 induction positively correlated with Bax and Noxa induction thus suggesting a pro-apoptotic function for $\mathrm{p} 21$ in the resistant cells. We should note that knockdown of IFITM1 also increased $\mathrm{E}_{2}$-induced cell death in AI-resistant MCF7:5C cells. The ability of $\mathrm{E}_{2}$ to induce mitochondrialmediated apoptosis in AI-resistant MCF-7:5C cells has previously been reported by our laboratory $[11,17]$; however, this is the first study to show that suppression of IFITM1 induces p21 and Bax expression and enhances $\mathrm{E}_{2}$-induced cell death in AI-resistant breast cancer cells.

IFITM1 is a member of the IFN-inducible transmembrane (IFITM) protein family that was originally identified as Leu-13, a leukocyte antigen that is a part of a membrane complex involved in the transduction of antiproliferative and homotypic adhesion signals in lymphocytes [56,57]. IFITM1 is highly induced by type 1 interferons (IFNs $\alpha$ and $\beta$ ) and is most well-known for its ability to restrict the replication of a number of enveloped and non-enveloped viruses [30]. More recently, IFITM1 has also been implicated in tumorigenesis and there is evidence that it can positively or negatively regulate cell proliferation depending on the tumor cell type $[25,27,31,32,40]$. In particular, IFITM1 overexpression has been shown to inhibit proliferation in hepatoma cells [29] and its constitutive overexpression has been shown to positively correlate with improved survival in chronic myeloid leukemia patients [25]. In contrast, upregulation of IFITM1 expression has been reported to play a critical role in both the precancerous stage and carcinogenesis in patients with gastric mucosa infected with Helicobacter pylori and cervical cancer [33]. In addition, there is evidence that IFITM1 overexpression induces tumor resistance to natural killer (NK) cells in gastric tumor cells and it facilitates migration and invasion of gastric cancer cells [29]. More recently, investigators have reported that overexpression of IFITM1 promotes head and neck tumor invasion in the early stages of disease progression by mediating the expression of molecules downstream, including matrix metalloproteinases 12 and 13 [32].

Our data provide strong evidence that constitutive overexpression of IFITM1 is driven by IFN $\alpha$ through activation of the canonical signaling pathway and that STAT1 and STAT2 play a critical role. In particular, we found that p-STAT1 and p-STAT2 (Figure 3F) were constitutively overexpressed in our resistant cells and that knockdown of IFN $\alpha$ dramatically reduced their expression in the cells. Furthermore, we found that knockdown of STAT1 and STAT2 dramatically reduced IFITM1 expression in the resistant cells. However, we should note that knockdown of IFN $\alpha$ or neutralizing IFNAR1/2 did not completely suppress IFITM1 expression in the resistant cells, which suggests that IFITM1 constitutive overexpression might be regulated by other mechanisms. Indeed, recent studies suggest that IFITM1 expression is regulated by the chromatin remodeling complexes (CRCs) consisting of BRG (Brahma-related gene) and BAF (BRMassociated factor), which work in concert with histone modification enzymes such as cyclic AMP-responsiveelement binding protein (CREB)-binding protein and/or p300 (CBP/p300) to bring about the regulation of IFITM1 and other IFN $\alpha$-target genes [58,59]. The BAF complexes are thought to prime the IFITM1 promoter by disrupting the nucleosome that covers the ISRE which then leads to constitutive expression of IFITM1, as demonstrated in our working model in Figure 9. Future studies will be aimed at determining how IFITM1 and other ISGs are regulated by the BRG/BAF complex in the resistant cells.

\section{Conclusions}

In summary, overexpression of ISGs and their protein products are emerging as important contributors to development of clinical neoplasia and drug resistance in many types of cancers. In our study, we demonstrated that several ISGs including IFITM1, STAT1 and PLSCR1 and their encoded proteins are constitutively overexpressed in AI-resistant breast cancer cells and AIresistant tumors and that their overexpression provides a survival advantage in the resistant cells. Furthermore, we showed that targeting ISGs, especially IFITM1, sensitized AI-resistant breast cancer cells to estrogen-induced cell death and it blocked the ability of these cells to migrate and invade. This finding has important clinical implications for patients with AI-resistant breast cancer because it suggests that altered interferon signaling might play a role in tumor progression and possibly the development of AI resistance. Future studies will need to address how and why interferon response genes are altered during resistance and whether an altered immune response gene profile can predict which patient will benefit from AI therapy and which patient will develop resistance following treatment. 


\section{Additional files}

Additional file 1: Figure S1. Overexpression of ISGs in Al-resistant MCF-7:5C cells as compared to parental MCF-7 cells. Total RNA was extracted from each cell line and mRNA expression of the ISGs shown above was determined by real-time PCR using PUM1 as the internal control. Primer sequences for the ISGs shown above are described in materials and methods. Fold change was calculated using the $\Delta \Delta C T$ method and is displayed as relative to MCF-7 cells (control). Values are means of triplicate measurements \pm SD from two independent experiments.

Additional file 2: Figure S2. Activation of interferon signaling pathway in parental MCF-7 and Al-resistant MCF-7:5C cells in response to INF-a. (A) MCF-7 and (B) MCF-7:5C cells were incubated with IFN-a $(1000 \mathrm{U} / \mathrm{ml})$ for the indicated time points. The cell extracts were examined by Western blotting using anti-PLSCR1, anti-IFITM1, anti-STAT1, anti-STAT2 and anti-b-actin. The protein levels were quantified using the ImageJ software (downloaded from $\mathrm{NIH}$ website) and normalized as the ratio relate to $\beta$-actin. ${ }^{*} P<0.05$ or ${ }^{* *} P<0.01$ versus control.

Additional file 3: Figure S3. Activation of IFN signaling pathway in parental MCF-7 and Al-resistant MCF-7:5C cells in response to IFN-a. MCF-7 and MCF-7:5C cells were treated with $100 \mathrm{U} / \mathrm{mL}$ IFN- $a$ and harvested at the indicated time points. mRNA expression of IFITM1, PLSCR1 and STAT1was measured using RT-PCR and calculated using the $\triangle \Delta C T$ method relative to PUM1. mRNA expression is given as fold change over control (time zero). Values shown are means of triplicate measurements \pm SD from three independent experiments.

Additional file 4: Figure S4. IFITM1 knockdown increases cell death in Al-resistant breast cancer cells. (A, top panel) MCF-7:5C cells were transfected with control shRNA (shCon), IFITM1 shRNA (shIFITM1) for 24 hours and then treated with 1 nM E2 for an additional 72 hours. Cell extracts were subject to Western blotting for the level of IFITM1 and PARP protein (top panel). Membranes were also stripped and reprobed for $\beta$-actin, which was used as a loading control. (A, bottom panel) shIFITM1 mRNA level in resistant MCF-7:5C cells was determined by real-time PCR and normalized to PUM1. ${ }^{*} P<0.05$ versus shcontrol (shCon). (B) Cell proliferation was measured in resistant MCF-7:5C cells by MTT assay. All the illustrated data were performed in triplicate and are expressed as mean values of three independent experiments. Standard deviations are shown. ${ }^{*} P<0.05$ versus control; $\# P<0.05$ versus $E 2$ treatment. (C) MCF-7:5C cells were transfected with shCon or shIFITM1 and after 24 hours were exposed to E2 (1 nM) for an additional 72 hours. Cells were then stained with annexin V-FITC and PI for detection of apoptosis as described in Methods.

Additional file 5: Figure S5. Role of IFN-a in estradiol-induced cell death in resistant MCF-7:5C cells. Cells were transfected with silFNa or siCon for 24 hours and then further treated with $1 \mathrm{nM}$ estradiol (E2) for an additional 96 hours. In parallel experiments, we also pre-treated MCF-7:5C cells with $5 \mu \mathrm{g} / \mathrm{mL}$ a-IFNAR antibody (MAB1 155) for 4 hours and then treated with $1 \mathrm{nM}$ estradiol for an additional 96 hours. At the 96 hour time point cells were harvested and proliferation was determined by MTT assay (top) and apoptosis was assessed by annexin V/PI staining (bottom). Data shown are expressed as mean values of three independent experiments.

Additional file 6: Figure S6. STAT1/STAT2 knockdown reduces IFITM1 expression in MCF-7:5C cells. Cells were transfected with sicontrol (siCon), STAT1 siRNA (siSTAT1), STAT2 siRNA (siSTAT2), or siSTAT1 and siSTAT2 for 48 hours and cells were harvested and analyzed by Western blot to assess STAT1, STAT2 and IFITM1 protein expression. Membranes were stripped and reprobed for $\beta$-actin, which was used as a loading control. Blots shown are representative of three separate experiments yielding similar results.

\section{Abbreviations}

Al: aromatase inhibitor; BAF: Brahma-associated factor; BRG: Brahma-related gene; BST2: bone marrow stromal cell antigen 2; CBP/p300: CREB-binding protein 300; CRCs: chromatin remodeling complexes; CREB: cyclic AMPresponsive-element binding protein; DAB: 3,3'-diaminobenzidine; (D)
MEM: (Dulbecco's) modified Eagle's medium; DMSO: dimethyl sulfoxide; $\mathrm{E}_{2}$ : 17ß-estradiol; ECL: enhanced chemiluminescence; ELISA: enzyme-linked immunosorbent assay; ER: estrogen receptor; ERa: estrogen receptor alpha; ER+: estrogen receptor-positive; ERE: estrogen response element; FBS: fetal bovine serum; HRP: horseradish peroxidase; ICC: immunocytochemistry; IF: immunofluorescence; IFI27: interferon-inducible protein 27; IFIT1: Interferoninduced protein with tetratricopeptide repeats 1; IFITM1: interferon induced transmembrane protein 1; IFNs: interferons; IFNR1/2: interferon receptor type 1 and 2; IgG: immunoglobulin G; IHC: immunohistochemistry; IR F-7: IFN regulatory factor 7; IRF9: IFN regulatory factor 9; ISGF3: IFN-stimulated gene factor 3; ISGs: interferon stimulated genes; ISREs: interferon stimulated response elements; JAK: Janus kinase 1 and 2; MTT: 3-(4,5-dimethylthiazol-2-YI)2,5-diphenyltetrazolium bromide; NK: natural killer; OAS 1,2,3: 2'-5'oligoadenylate synthetase 1,2,3, PARP, poly ADP ribose polymerase; PBS: phosphate-buffered saline; PCR: polymerase chain reaction; PI: propidium iodide; PLSCR1: phospholipid scramblase 1; SDS-PAGE: sodium dodecyl sulfatepolyacrylamide gel electrophoresis; SI: staining index; SOCS1: suppressor of cytokine signaling 1; STAT1,2: signal transducer and activator of transcription 1,2; TTP: time to disease progression; U-ISGF3: unphosphorylated IFN-stimulated gene factor 3; 4OHT: 4-hydoxytamoxifen.

\section{Competing interests}

The authors declare that they have no competing interests.

\section{Authors' contributions}

JLW conceived the study, participated in the research design and implementation of the study, analyzed and interpreted the data, and drafted the manuscript. HJC performed the experiments, analyzed the data, and drafted the manuscript. AL performed the experiments, analyzed the data, and drafted the manuscript. JO performed some of the experiments and helped to draft the manuscript. RJ performed all of the IHC experiments. PJS provided reagents used for IF and IHC studies and helped with the discussion of the manuscript. All authors read and approved the final manuscript.

\section{Acknowledgements}

This work was supported by grants from the Department of Defense (W81XWH-12-1-0139; supporting JLW), National Cancer Institute (K01CA120051; supporting $J(W)$, and by start-up funds from the University of Kansas Medical Center (supporting JLW, HJC, JO, AL). The funders had no role in study design, data collection and analysis, decision to publish, or preparation of the manuscript. We would like to thank the KU Cancer Center's CCSG (P30 CA168524) Biospecimen Repository Core and the Fox Chase Cancer Center Biosample Repository Core Facilities for providing the breast tumor samples used in this study. We would also like to acknowledge the Flow Cytometry Core and the Cell Imaging Core Facilities at KUMC.

\section{Author details}

${ }^{1}$ Department of Cancer Biology, University of Kansas Medical Center, Kansas City 66160, KS, USA. ${ }^{2}$ Department of Physiology, University of Kansas Medical Center, Kansas City 66160, KS, USA. ${ }^{3}$ Cancer Biology Program, Research Institute of Fox Chase Cancer Center, Philadelphia 19111, PA, USA.

${ }^{4}$ Department of Pathology and Laboratory Medicine, University of Rochester, Rochester 14642, NY, USA.

Received: 4 April 2014 Accepted: 15 December 2014 Published online: 15 January 2015

\section{References}

1. Mouridsen H, Gershanovich M, Sun Y, Perez-Carrion R, Boni C, Monnier A, et al. Phase III study of letrozole versus tamoxifen as first-line therapy of advanced breast cancer in postmenopausal women: analysis of survival and update of efficacy from the International Letrozole Breast Cancer Group. J Clin Oncol. 2003;21:2101-9.

2. Chumsri S, Howes T, Bao T, Sabnis G, Brodie A. Aromatase, aromatase inhibitors, and breast cancer. J Steroid Biochem Mol Biol. 2011;125:13-22.

3. Goss PE, Strasser K. Aromatase inhibitors in the treatment and prevention of breast cancer. J Clin Oncol. 2001;19:881-94.

4. Jordan VC, Brodie AM. Development and evolution of therapies targeted to the estrogen receptor for the treatment and prevention of breast cancer. Steroids. 2007;72:7-25. 
5. Geisler J, King N, Dowsett M, Ottestad L, Lundgren S, Walton P, et al. Influence of anastrozole (Arimidex), a selective, non-steroidal aromatase inhibitor, on in vivo aromatisation and plasma oestrogen levels in postmenopausal women with breast cancer. Br J Cancer. 1996;74:1286-91.

6. Miller WR, Larionov AA. Understanding the mechanisms of aromatase inhibitor resistance. Breast Cancer Res. 2012;14:201.

7. Ellis MJ, Gao F, Dehdashti F, Jeffe DB, Marcom PK, Carey LA, et al. Lowerdose vs high-dose oral estradiol therapy of hormone receptor-positive, aromatase inhibitor-resistant advanced breast cancer: a phase 2 randomized study. JAMA. 2009;302:774-80.

8. Iwase H, Yamamoto Y, Yamamoto-lbusuki M, Murakami Kl, Okumura Y, Tomita S, et al. Ethinylestradiol is beneficial for postmenopausal patients with heavily pre-treated metastatic breast cancer after prior aromatase inhibitor treatment: a prospective study. Br J Cancer. 2013;109:1537-42.

9. Jiang SY, Wolf DM, Yingling JM, Chang C, Jordan VC. An estrogen receptor positive MCF-7 clone that is resistant to antiestrogens and estradiol. Mol Cell Endocrinol. 1992;90:77-86.

10. Lewis JS, Cheng D, Jordan VC. Targeting oestrogen to kill the cancer but not the patient. Br J Cancer. 2004;90:944-9.

11. Lewis JS, Meeke K, Osipo C, Ross EA, Kidawi N, Li T, et al. Intrinsic mechanism of estradiol-induced apoptosis in breast cancer cells resistant to estrogen deprivation. J Natl Cancer Inst. 2005;97:1746-59.

12. Lewis JS, Osipo C, Meeke K, Jordan VC. Estrogen-induced apoptosis in a breast cancer model resistant to long-term estrogen withdrawal. J Steroid Biochem Mol Biol. 2005;94:131-41.

13. Masamura S, Santner SJ, Heitjan DF, Santen RJ. Estrogen deprivation causes estradiol hypersensitivity in human breast cancer cells. J Clin Endocrinol Metab. 1995:80:2918-25.

14. Song RX, Mor G, Naftolin F, McPherson RA, Song J, Zhang Z, et al. Effect of long-term estrogen deprivation on apoptotic responses of breast cancer cells to 17beta-estradiol. J Natl Cancer Inst. 2001;93:1714-23.

15. Lewis-Wambi JS, Jordan VC. Estrogen regulation of apoptosis: how can one hormone stimulate and inhibit? Breast Cancer Res. 2009;11:206.

16. Lewis-Wambi JS, Kim HR, Wambi C, Patel R, Pyle JR, Klein-Szanto AJ, et al. Buthionine sulfoximine sensitizes antihormone-resistant human breast cancer cells to estrogen-induced apoptosis. Breast Cancer Res. 2008;10:R104.

17. Ariazi EA, Cunliffe HE, Lewis-Wambi JS, Slifker MJ, Willis AL, Ramos P, et al. Estrogen induces apoptosis in estrogen deprivation-resistant breast cancer through stress responses as identified by global gene expression across time. Proc Natl Acad Sci U S A. 2011;108:18879-86.

18. Stark GR, Kerr IM, Williams BR, Silverman RH, Schreiber RD. How cells respond to interferons. Annu Rev Biochem. 1998;67:227-64.

19. Borden EC, Sen GC, Uze G, Silverman RH, Ransohoff RM, Foster GR, et al. Interferons at age 50: past, current and future impact on biomedicine. Nat Rev Drug Discov. 2007;6:975-90.

20. Lewin AR, Reid LE, McMahon M, Stark GR, Kerr IM. Molecular analysis of a human interferon-inducible gene family. Eur J Biochem. 1991;199:417-23.

21. Critchley-Thorne RJ, Simons DL, Yan N, Miyahira AK, Dirbas FM, Johnson DL, et al. Impaired interferon signaling is a common immune defect in human cancer. Proc Natl Acad Sci U S A. 2009;106:9010-5.

22. Schreiber RD, Old LJ, Smyth MJ. Cancer immunoediting: integrating immunity's roles in cancer suppression and promotion. Science. 2011;331:1565-70

23. Khodarev NN, Beckett M, Labay E, Darga T, Roizman B, Weichselbaum RR. STAT1 is overexpressed in tumors selected for radioresistance and confers protection from radiation in transduced sensitive cells. Proc Natl Acad Sci U S A. 2004:101:1714-9.

24. Lewis-Wambi JS, Cunliffe HE, Kim HR, Willis AL, Jordan VC. Overexpression of CEACAM6 promotes migration and invasion of oestrogen-deprived breast cancer cells. Eur J Cancer. 2008:44:1770-9.

25. Akyerli CB, Beksac M, Holko M, Frevel M, Dalva K, Ozbek U, et al. Expression of IFITM1 in chronic myeloid leukemia patients. Leuk Res. 2005;29:283-6.

26. Deblandre GA, Marinx OP, Evans SS, Majjaj S, Leo O, Caput D, et al. Expression cloning of an interferon-inducible 17-kDa membrane protein implicated in the control of cell growth. J Biol Chem. 1995;270:23860-6.

27. Ackrill AM, Reid LE, Gilbert CS, Gewert DR, Porter AC, Lewin AR, et al. Differential response of the human 6-16 and 9-27 genes to alpha and gamma interferons. Nucleic Acids Res. 1991;19:591-8.

28. Bradbury LE, Kansas GS, Levy S, Evans RL, Tedder TF. The CD19/CD21 signal transducing complex of human B lymphocytes includes the target of antiproliferative antibody-1 and Leu-13 molecules. J Immunol. 1992;149:2841-50.
29. Yang $Y$, Lee JH, Kim KY, Song HK, Kim JK, Yoon SR, et al. The interferoninducible 9-27 gene modulates the susceptibility to natural killer cells and the invasiveness of gastric cancer cells. Cancer Lett. 2005;221:191-200.

30. Huang IC, Bailey CC, Weyer JL, Radoshitzky SR, Becker MM, Chiang JJ, et al. Distinct patterns of IFITM-mediated restriction of filoviruses, SARS coronavirus, and influenza A virus. PLoS Pathog. 2011;7:e1001258.

31. Andreu P, Colnot S, Godard C, Laurent-Puig P, Lamarque D, Kahn A, et al. Identification of the IFITM family as a new molecular marker in human colorectal tumors. Cancer Res. 2006;66:1949-55.

32. Hatano H, Kudo Y, Ogawa I, Tsunematsu T, Kikuchi A, Abiko Y, et al. IFNinduced transmembrane protein 1 promotes invasion at early stage of head and neck cancer progression. Clin Cancer Res. 2008;14:6097-105.

33. Hofman VJ, Moreilhon C, Brest PD, Lassalle S, Le Brigand K, Sicard D, et al. Gene expression profiling in human gastric mucosa infected with Helicobacter pylori. Mod Pathol. 2007;20:974-89.

34. Zhou Q, Ben-Efraim I, Bigcas JL, Junqueira D, Wiedmer T, Sims PJ. Phospholipid scramblase 1 binds to the promoter region of the inositol 1,4,5-triphosphate receptor type 1 gene to enhance its expression. J Biol Chem. 2005;280:35062-8.

35. Zhou Q, Zhao J, Wiedmer T, Sims PJ. Normal hemostasis but defective hematopoietic response to growth factors in mice deficient in phospholipid scramblase 1. Blood. 2002;99:4030-8.

36. Huang Y, Zhao Q, Zhou CX, Gu ZM, Li D, Xu HZ, et al. Antileukemic roles of human phospholipid scramblase 1 gene, evidence from inducible PLSCR1expressing leukemic cells. Oncogene. 2006;25:6618-27.

37. Silverman RH, Halloum A, Zhou A, Dong B, Al-Zoghaibi F, Kushner D, et al. Suppression of ovarian carcinoma cell growth in vivo by the interferoninducible plasma membrane protein, phospholipid scramblase 1. Cancer Res. 2002;62:397-402.

38. Sims PJ, Wiedmer T. Induction of cellular procoagulant activity by the membrane attack complex of complement. Semin Cell Biol. 1995;6:275-82.

39. Wiedmer T, Zhou Q, Kwoh DY, Sims PJ. Identification of three new members of the phospholipid scramblase gene family. Biochim Biophys Acta. 2000;1467:244-53.

40. http://rsb.info.nih.gov/ij/download.html

41. Gongora C, Candeil L, Vezzio N, Copois V, Denis V, Breil C, et al. Altered expression of cell proliferation-related and interferon-stimulated genes in colon cancer cells resistant to SN38. Cancer Biol Ther. 2008;7:822-32.

42. Khodarev NN, Roach P, Pitroda SP, Golden DW, Bhayani M, Shao MY, et al. STAT1 pathway mediates amplification of metastatic potential and resistance to therapy. PLoS One. 2009;4:e5821.

43. Khodarev NN, Roizman B, Weichselbaum RR. Molecular pathways: interferon/stat1 pathway: role in the tumor resistance to genotoxic stress and aggressive growth. Clin Cancer Res. 2012;18:3015-21.

44. Roberts D, Schick J, Conway S, Biade S, Laub PB, Stevenson JP, et al. Identification of genes associated with platinum drug sensitivity and resistance in human ovarian cancer cells. Br J Cancer. 2005;92:1149-58.

45. Dunbier AK, Ghazoui Z, Anderson H, Salter J, Nerurkar A, Osin P, et al. Molecular profiling of aromatase inhibitor-treated postmenopausal breast tumors identifies immune-related correlates of resistance. Clin Cancer Res. 2013;19:2775-86

46. Perou CM, Jeffrey SS, van de Rijn M, Rees CA, Eisen MB, Ross DT, et al. Distinctive gene expression patterns in human mammary epithelial cells and breast cancers. Proc Natl Acad Sci U S A. 1999;96:9212-7.

47. Rickardson L, Fryknas M, Dhar S, Lovborg H, Gullbo J, Rydaker M, et al. Identification of molecular mechanisms for cellular drug resistance by combining drug activity and gene expression profiles. Br J Cancer. 2005;93:483-92.

48. Yoshimura A, Naka T, Kubo M. SOCS proteins, cytokine signalling and immune regulation. Nat Rev Immunol. 2007;7:454-65.

49. Cheon H, Stark GR. Unphosphorylated STAT1 prolongs the expression of interferon-induced immune regulatory genes. Proc Natl Acad Sci U S A. 2009;106:9373-8.

50. de Visser KE, Eichten A, Coussens LM. Paradoxical roles of the immune system during cancer development. Nat Rev Cancer. 2006;6:24-37.

51. Leonova Kl, Brodsky L, Lipchick B, Pal M, Novototskaya L, Chenchik AA, et al. p53 cooperates with DNA methylation and a suicidal interferon response to maintain epigenetic silencing of repeats and noncoding RNAs. Proc Natl Acad Sci U S A. 2013;110:E89-98.

52. el-Deiry WS, Tokino T, Velculescu VE, Levy DB, Parsons R, Trent JM, et al. WAF1, a potential mediator of p53 tumor suppression. Cell. 1993;75:817-25. 
53. Asada M, Yamada T, Ichijo H, Delia D, Miyazono K, Fukumuro K, et al. Apoptosis inhibitory activity of cytoplasmic p21(Cip1/NAF1) in monocytic differentiation. EMBO J. 1999;18:1223-34.

54. Zhou BP, Liao Y, Xia W, Spohn B, Lee MH, Hung MC. Cytoplasmic localization of p21Cip1/WAF1 by Akt-induced phosphorylation in HER-2/ neu-overexpressing cells. Nat Cell Biol. 2001;3:245-52.

55. Braun F, Bertin-Ciftci J, Gallouet AS, Millour J, Juin P. Serum-nutrient starvation induces cell death mediated by Bax and Puma that is counteracted by p21 and unmasked by BCl-x(L) inhibition. PLoS One. 2011;6:e23577.

56. Chen YX, Welte K, Gebhard DH, Evans RL. Induction of T cell aggregation by antibody to a 16kd human leukocyte surface antigen. J Immunol. 1984;133:2496-501.

57. Matsumoto AK, Martin DR, Carter RH, Klickstein LB, Ahearn JM, Fearon DT. Functional dissection of the CD21/CD19/TAPA-1/Leu-13 complex of B lymphocytes. J Exp Med. 1993;178:1407-17.

58. Chi T. A BAF-centred view of the immune system. Nat Rev Immunol. 2004:4:965-77

59. Cui K, Tailor P, Liu H, Chen X, Ozato K, Zhao K. The chromatin-remodeling BAF complex mediates cellular antiviral activities by promoter priming. Mol Cell Biol. 2004;24:4476-86.

\section{Submit your next manuscript to BioMed Central and take full advantage of:}

- Convenient online submission

- Thorough peer review

- No space constraints or color figure charges

- Immediate publication on acceptance

- Inclusion in PubMed, CAS, Scopus and Google Scholar

- Research which is freely available for redistribution 